ARTICLE

Received 29 Dec 2015 | Accepted 10 Feb 2016 | Published 1 Apr 2016

DOI: $10.1038 /$ ncomms11004

OPEN

\title{
Neutrophil-specific deletion of the CARD9 gene expression regulator suppresses autoantibody-induced inflammation in vivo
}

Tamás Németh ${ }^{1,2}$, Krisztina Futosi ${ }^{1}$, Cassian Sitaru ${ }^{3}$, Jürgen Ruland ${ }^{4} \&$ Attila Mócsai ${ }^{1,2}$

Neutrophils are terminally differentiated cells with limited transcriptional activity. The biological function of their gene expression changes is poorly understood. CARD9 regulates transcription during antifungal immunity but its role in sterile inflammation is unclear. Here we show that neutrophil CARD9 mediates pro-inflammatory chemokine/cytokine but not lipid mediator release during non-infectious inflammation. Genetic deficiency of CARD9 suppresses autoantibody-induced arthritis and dermatitis in mice. Neutrophil-specific deletion of CARD9 is sufficient to induce that phenotype. Card9 $9^{-/-}$neutrophils show defective immune complex-induced gene expression changes and pro-inflammatory chemokine/cytokine release but normal $\mathrm{LTB}_{4}$ production and other short-term responses. In vivo deletion of CARD9 reduces tissue levels of pro-inflammatory chemokines and cytokines but not $\mathrm{LTB}_{4}$. The CARD9-mediated signalling pathway involves Src-family kinases, Syk, PLC $\gamma 2, B c 110 /$ Malt1 and NFKB. Collectively, CARD9-mediated gene expression changes within neutrophils play important roles during non-infectious inflammation in vivo and CARD9 acts as a divergence point between chemokine/cytokine and lipid mediator release.

\footnotetext{
${ }^{1}$ Department of Physiology, Semmelweis University School of Medicine, 1094 Budapest, Hungary. ${ }^{2}$ MTA-SE 'Lendület' Inflammation Physiology Research Group of the Hungarian Academy of Sciences and Semmelweis University, 1094 Budapest, Hungary. ${ }^{3}$ Department of Dermatology, University Hospital Freiburg and BIOSS Centre for Biological Signalling Studies, 79104 Freiburg, Germany. ${ }^{4}$ Department of Clinical Chemistry and Pathobiochemistry, Technical University of Munich, 81675 Munich, Germany. Correspondence and requests for materials should be addressed to A.M. (email: mocsai.attila@med.semmelweis-univ.hu).
} 
$\mathrm{N}$ eutrophils are short-lived, terminally differentiated cells that play critical roles in antimicrobial host defence and also contribute to autoimmune and other non-infectious inflammatory processes ${ }^{1-3}$. Unlike the long-lived macrophages and dendritic cells, neutrophils have limited transcriptional activity but instead show robust short-term effector functions such as phagocytosis, respiratory burst, degranulation or NET release. The dissociation of neutrophil function from gene expression is best exemplified by the fact that anuclear neutrophils that have expelled their DNA through NETosis are still capable of performing various in vivo antimicrobial functions ${ }^{4}$. Based on their short lifespan, limited transcriptional activity and robust short-term effector functions, neutrophils are generally believed to be simple effector cells of the immune and inflammatory reaction.

However, neutrophils have also been shown to be able to upregulate pro-inflammatory gene expression and to release various chemokines and cytokines ${ }^{5,6}$. Those non-conventional functional responses may indicate a more general role of neutrophils in the orchestration of the immune/inflammatory response $e^{1,3,6}$. Unfortunately, it is still unclear whether inflammation-related gene expression changes in neutrophils (and the resulting chemokine/cytokine production) are just evolutionary remnants from the macrophage-related origin of these cells, or they play an important functional role during the in vivo inflammation process. This uncertainty is primarily due to the fact that none of the currently available in vivo models allow suppression of gene expression changes in such a manner that it is both selective for neutrophils and it also retains other functional responses of neutrophils intact.

Caspase recruitment domain-containing protein 9 (CARD9) is an intracellular adapter protein primarily expressed in myeloidlineage cells and couples C-type lectin receptors to NFKBmediated gene expression ${ }^{7}$. CARD9 plays a critical role in host defence against fungal pathogens in both mice $e^{8-10}$ and humans ${ }^{11,12}$, and it is also involved in immunity against other microbial infections ${ }^{7,13}$. In addition to its antimicrobial function, human genetic studies have also linked CARD9 to highly prevalent human diseases of non-infectious origin such as inflammatory bowel disease ${ }^{14-17}$, ankylosing spondylitis $^{18,19}$, rheumatoid arthritis ${ }^{20}$ or IgA nephropathy ${ }^{21}$. However, it is still unclear whether CARD9 indeed participates in non-infectious inflammation and if so, what are the cellular and molecular pathways involved. In addition, though the analysis of CARD9 function has so far focused on dendritic cells and macrophages, CARD9 is also present in neutrophils ${ }^{12,22}$ and the ImmGen database ${ }^{23}$ indicates that neutrophils express the highest level of CARD9 within the immune system. Unfortunately, the role of CARD9 in neutrophils is still very poorly understood.

Autoantibody-induced sterile inflammation is an important component of autoimmune disease pathogenesis. Its experimental models ${ }^{24-26}$ mimic important aspects of human rheumatoid arthritis, bullous pemphigoid and epidermolysis bullosa acquisita. Autoantibody-induced inflammation is mediated by sequential activation of lipid $\left(\mathrm{LTB}_{4}\right)$, cytokine and chemokine cascades ${ }^{27}$. Neutrophils are critically involved in autoantibody-induced sterile inflammation ${ }^{2,28}$ and we have previously shown that autoantibody-induced inflammation is mediated by signalling through Src-family kinases, Syk and PLC 2 (refs 29-32). However, it is at present unclear how signalling downstream of those receptor-proximal molecules triggers lipid, chemokine and cytokine release.

The lack of knowledge on the contribution of neutrophil gene expression to in vivo inflammation, on the role of CARD9 in non-infectious inflammation and neutrophil function and on how receptor-proximal signalling molecules are coupled to inflammatory mediator release, prompted us to investigate the role of CARD9 in autoantibody-mediated in vivo inflammation models. Our results indicate that CARD9 mediates autoantibodyinduced inflammation by acting as a divergence point downstream of receptor-proximal signalling molecules triggering chemokine and cytokine but not lipid mediator $\left(\mathrm{LTB}_{4}\right)$ release. Importantly, lineage-specific studies revealed that those functions are primarily linked to CARD9 expression within neutrophils, indicating a critical contribution of neutrophil gene expression and chemokine/cytokine release to the overall in vivo inflammatory reaction.

\section{Results}

The role of CARD9 in autoantibody-induced arthritis. To test the role of CARD9 in non-infectious inflammation, we tested the effect of CARD9 deficiency on autoantibody-induced arthritis development in the $\mathrm{K} / \mathrm{B} \times \mathrm{N}$ serum-transfer model ${ }^{30}$ We have used two independent CARD9-deficient mouse strains (Supplementary Fig. 1a) that were homozygous either for the conventional Card $9^{\operatorname{tm} 1 \text { Jrld }}$ knockout mutation (referred to as $\operatorname{Card} 9^{-I-}$ mice) or for the so-called knockout-

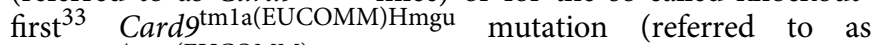
Card9 $9^{-1-}$ (EUCOMM) mice). CARD9 was absent from bone marrow (Supplementary Fig. 1b) and spleen (Supplementary Fig. 1c) cell lysates of both mutant strains. As indicated in Fig. 1a, Card $9^{-1-}$ mice showed substantially reduced signs of arthritis development. Quantification of the visible clinical signs (Fig. 1b; $P=0.0028$; two-way analysis of variance (ANOVA)), ankle thickening (Fig. 1c; $P=0.0047$; two-way ANOVA) and the ability of the mice to hold on to the bottom of a wire grid (Fig. 1d; $P=2 \times 10^{-4}$; two-way ANOVA) all confirmed highly significant protection from disease development. Similarly, Card $9^{-1-}$ (EUCOMM) mice were also strongly protected from visible signs of arthritis (Fig. 1e; $P=6.6 \times 10^{-4}$; two-way ANOVA) and ankle thickening (Fig. 1f; $P=0.0038$; two-way ANOVA). Therefore, CARD9 plays a major role in the development of autoantibody-induced arthritis.

We have also generated bone marrow chimeras by transplanting CARD9-deficient bone marrow cells to lethally irradiated wild-type recipients. Similar to intact mice, $\operatorname{Card9^{-1}-}$ bone marrow chimeras also showed partial protection from arthritis development in the $\mathrm{K} / \mathrm{B} \times \mathrm{N}$ serum-transfer model (Supplementary Figs $2 \mathrm{a}-\mathrm{d} ; P$ values between $9.1 \times 10^{-11}$ and $1.6 \times 10^{-4}$; two-way ANOVA), indicating a role for CARD9 in a radiosensitive hematopoietic compartment.

The role of CARD9 in autoantibody-induced skin blistering. We have also tested the effect of CARD9 deficiency on dermatitis triggered by systemic administration of antibodies against collagen VII (a mouse model of the human blistering skin disease epidermolysis bullosa acquisita). Card $9^{-/-}$mice were substantially, though not completely protected from the visible skin disease (Fig. 2a), which was also confirmed by quantitative analysis of the body surface area affected (Fig. 2b; $P=0.017$; two-way ANOVA) and the overall disease severity score (Fig. 2c; $P=0.022$; two-way ANOVA). This was not due to the reduced circulating autoantibody concentration since serum levels of collagen VII-specific IgG were similar in wild-type and Card $9^{-9}$ mice (Fig. 2d; $P=0.95$; two-way ANOVA).

Role of CARD9 in leukocyte recruitment and migration. Flow cytometric analysis of myeloid cells in the synovial infiltrate (Fig. 3a,b) revealed reduced accumulation of neutrophils $(P=0.0041$; Student's $t$-test $)$ and macrophages $(P=0.026$; 
a

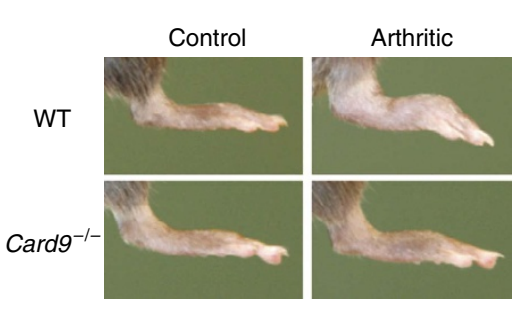

C

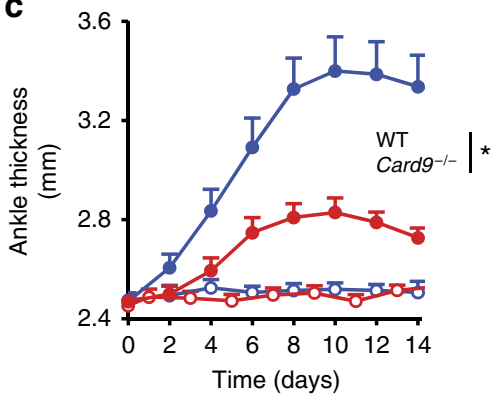

e

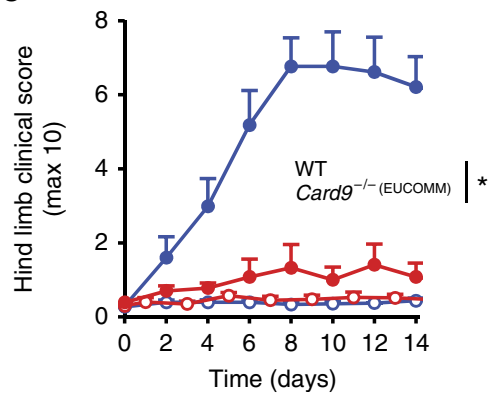

b

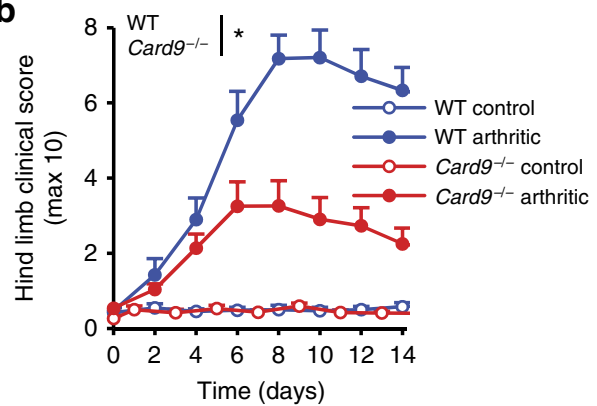

d

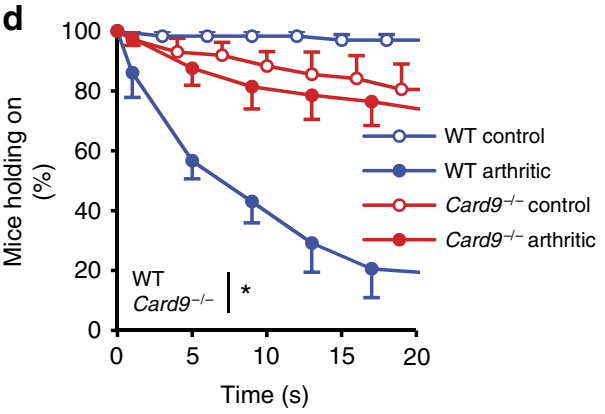

f

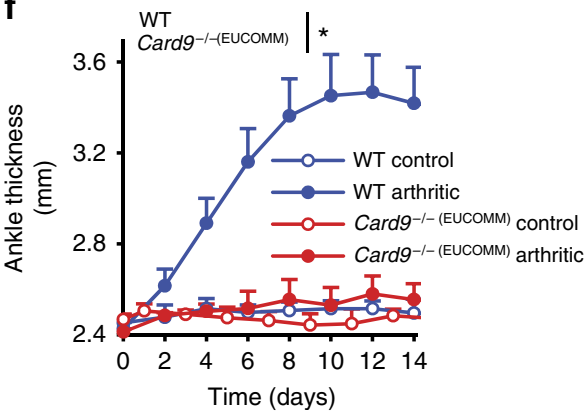

Figure 1 | CARD9 is important for the development of autoantibody-induced arthritis. Intact wild type (WT), Card9-/ - (a-d) or Card9-/- (EUCOMM) $(\mathbf{e}, \mathbf{f})$ mice were injected with $\mathrm{B} \times \mathrm{N}$ (control) or $\mathrm{K} / \mathrm{B} \times \mathrm{N}$ (arthritic) serum i.p. on day 0 . Arthritis development was followed by photographing on day 7 (a), clinical scoring of the hind limbs (b,e), ankle-thickness measurement (c,f) and an articular function test (hanging on a wire grid; (d)). Images are representative of, and quantitative data show mean and s.e.m. from 8 to 9 control and 12 to 13 arthritic serum-treated individual mice per group from four independent experiments (a-d) or 5 to 6 control and 8 to 9 arthritic serum-treated mice per group from three independent experiments (e,f).

(d) Results from functional test performed 12 times on each mouse between days $7-10 .{ }^{\star} P<0.05$ (two-way ANOVA); see the text for actual $P$ values.

Student's $t$-test) at the site of inflammation in $\operatorname{Card9}^{-1-}$ mice subjected to $\mathrm{K} / \mathrm{B} \times \mathrm{N}$ serum-transfer arthritis. To reveal whether that reduction was due to a cell-autonomous migration defect, we generated mixed bone marrow chimeras carrying CD45.1expressing wild type, along with CD45.2-expressing wild type or Card $9^{-I}$ hematopoietic tissues (WT: WT and WT: Card9 ${ }^{-1-}$ chimeras, respectively). Those chimeras were subjected to $\mathrm{K} / \mathrm{B} \times \mathrm{N}$ serum-transfer arthritis and the ability of myeloid cells from the different genotypes to infiltrate the inflamed synovium was tested by comparing the ratio of CD45.1-expressing and CD45.2-expressing cells in the peripheral blood and synovial infiltrate. As shown in Fig. $3 c$ and Supplementary Fig. 3a, no significant difference between the percentage of CD45.2-positive neutrophils in the blood and synovium was observed in any of the mixed bone marrow chimeras irrespective of the genotype (wild type or $\mathrm{Card9}^{-/-}$) of the CD45.2-positive population $(P=0.80$ for normalized data shown in Supplementary Fig. 3a; Student's $t$-test). Similarly, the percentage of CD45.2-positive monocytes in the blood was always similar to that of CD45.2positive macrophages in the synovium, irrespective of the genotype of the CD45.2-positive cells (Fig. 3d and Supplementary Fig. 3b; $P=0.56$; Student's $t$-test). Those results indicated that
Card9 ${ }^{-1}$ myeloid cells did not have an intrinsic migration defect in vivo.

We also tested the intrinsic migratory capacity of neutrophils in in vitro transwell assays. As shown in Fig. 3e, the Card9 $9^{-1-}$ mutation did not affect the migration of neutrophils towards fMLP ( $P=0.71$; two-way ANOVA), MIP-2 (CXCL2; $P=0.53$; two-way ANOVA) or $\mathrm{LTB}_{4}(P=0.92$; two-way ANOVA $)$ as chemoattractants either.

Taken together, Card9 $9^{-1-}$ myeloid cells show partially reduced accumulation at the site of inflammation despite no cell-autonomous migration defect.

Decreased chemokine and cytokine but not $\mathrm{LTB}_{4}$ levels in vivo. To resolve the apparent contradiction between partially reduced accumulation but normal intrinsic migratory capacity of Card9 $9^{-1-}$ myeloid cells, we hypothesized that CARD9 was required for the generation of an appropriate inflammatory (chemoattractant) tissue microenvironment. Therefore, we tested the presence of various pro-inflammatory mediators in the synovial infiltrate. As shown in Fig. 4a,b, the $\operatorname{Card} 9^{-1}$ mutation led to a strong reduction of the levels of various chemokines acting on myeloid cells, including KC (CXCL1; $P=0.011$; two-way 
a
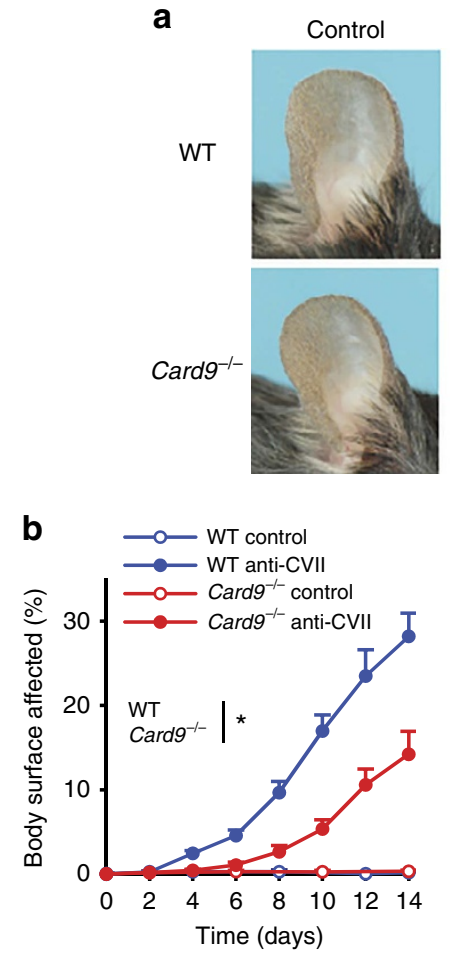

Anti-CVII

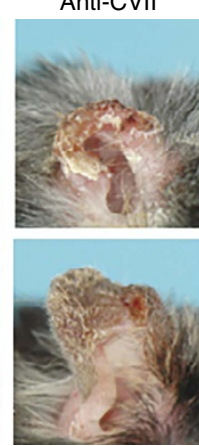

C

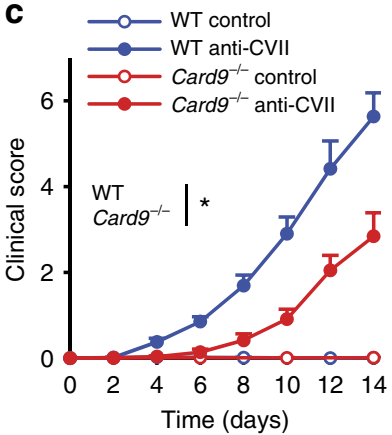

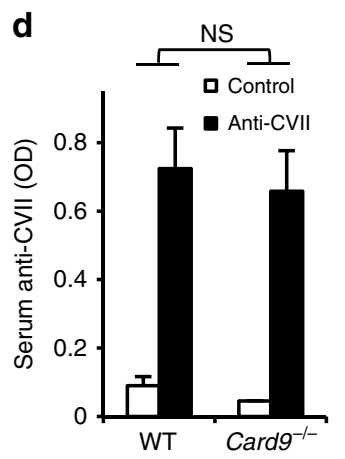

Figure 2 | CARD9 in autoantibody-induced skin blistering disease. Blistering skin disease was triggered in wild type (WT) and Card9-/intact mice or bone marrow chimeras by systemic injection of collagen VIIspecific (anti-CVII) antibodies. Skin disease was followed by photographing on day 14 (a) and clinical assessment of the total body surface affected (b) and the overall disease severity (c). The serum titre of anti-CVII antibodies was tested on day 6 by ELISA (d). Representative images (a) or mean and s.e.m. (b-c) from 7 to 9 control (2 intact and 5-7 bone marrow chimeric) and 13-14 anti-CVII-treated (2 intact and 11-12 bone marrow chimeric) mice per genotype from four independent experiments are shown. No difference between intact and chimeric mice of the same hematopoietic genotype was observed (not shown). (d) Mean and s.e.m. from 4 control and 12-13 anti-CVII-treated mice from five independent experiments are shown. ${ }^{\star} P<0.05$; NS, statistically not significant (two-way ANOVA); see the text for actual $P$ values.

ANOVA), MIP- $1 \alpha$ (CCL3; $P=0.0013$; two-way ANOVA) and MIP-2 (CXCL2; $P=0.027$; two-way ANOVA), as well as the IL-1 $\beta$ cytokine $\left(P=2.5 \times 10^{-5}\right.$; two-way ANOVA). Interestingly, however, the $\mathrm{Card}^{-1}$ - mutation did not affect the level of the lipid chemoattractant $\mathrm{LTB}_{4}$ at the site of inflammation (Fig. 4c; $P=0.77$; two-way ANOVA). Those results likely explain the substantially but not completely reduced accumulation of myeloid cells in the inflamed synovium.

Neutrophil CARD9 is required for in vivo inflammation. The importance of neutrophils in autoantibody-induced inflammation $^{28,34}$ and the apparent role of CARD9 in a radiosensitive hematopoietic compartment (Supplementary Fig. 2) raised the possibility that CARD9 expressed in neutrophils was required for the autoantibody-induced arthritis and dermatitis response. The availability of the Card $9^{\text {tmla(EUCOMM)Hmgu }}$ allele that allows further manipulation towards lineage-specific deletion provided a unique opportunity to test the functional relevance of CARD9 specifically within the neutrophil lineage.

Using FRT-mediated manipulation of the $\operatorname{Card} 9^{\mathrm{tmla}}$ (EUCOMM) Amgu knockout-first allele (Supplementary Fig. 4), we have generated mice carrying the Card $9^{\text {tmlc(EUCOMM) Hmgu }}$ (referred to as $\operatorname{Card} 9^{\text {flox }}$ ) floxed allele and bred those mice to MRP8-Cre ${ }^{35}$ transgene-expressing mice to generate MRP8$\mathrm{Cre}^{+} \operatorname{Card} 9^{\text {flox/flox }}$ (referred to as $\operatorname{Card} 9^{\Delta \mathrm{PMN}}$ ) mice with lineage-specific deletion of CARD9 specifically in the neutrophil compartment (Supplementary Fig. 4). As shown in Fig. 5a, FACSsorted $\mathrm{Card}^{-1}$ neutrophils had no detectable CARD9 expression, whereas the level of CARD9 was strongly reduced (though not completely absent) in similarly sorted $\operatorname{Card} 9^{\triangle \mathrm{PMN}}$ neutrophils. However, in agreement with prior studies showing high selectivity of the MRP8-Cre transgene ${ }^{35,36}$, the $\operatorname{Card9} 9^{\triangle \mathrm{PMN}}$ mutation did not affect CARD9 expression in bone marrowderived macrophages (Fig. 5b). Those results confirmed the effective and specific deletion of CARD9 from $\operatorname{Card} 9^{\triangle \mathrm{PMN}}$ neutrophils.

We next tested the effect of the Card $9^{\Delta \mathrm{PMN}}$ mutation on $\mathrm{K} / \mathrm{B} \times \mathrm{N}$ serum-transfer arthritis. As shown in Fig. $5 c$, both the $\operatorname{Card9}^{-1-} \quad\left(P=1.4 \times 10^{-6} ;\right.$ two-way ANOVA $)$ and the Card $9^{\triangle \mathrm{PMN}}\left(P=4 \times 10^{-4}\right.$; two-way ANOVA) mutations caused a substantial but incomplete reduction of the clinical arthritis score. Similarly, the ankle-thickening response (Fig. 5d) was reduced in both $\operatorname{Card9^{-1}}\left(P=4.3 \times 10^{-4}\right.$; two-way ANOVA $)$ and Card $9^{\triangle \mathrm{PMN}}(P=0.0069$; two-way ANOVA) mutants. Importantly, there was practically no difference between the effect of neutrophilspecific and complete CARD9 deficiency in either assay readouts tested ( $P$ values between 0.47 and 0.56; two-way ANOVA).

We have also subjected the same mutants to the autoantibodyinduced skin blistering disease model. As shown in Fig. 5e, both the $\operatorname{Card9}^{-1-}\left(P=4.6 \times 10^{-6}\right.$; two-way ANOVA $)$ and the $\operatorname{Card} 9^{\Delta \mathrm{PMN}}\left(P=1.7 \times 10^{-5}\right.$; two-way ANOVA) mutants were significantly but not completely protected from disease development defined as the body area affected. Similarly, the clinical score (Fig. 5f) was reduced in both $\operatorname{Card}^{-1-}\left(P=1.6 \times 10^{-4}\right.$; two-way ANOVA) and $\operatorname{Card}^{\Delta \mathrm{PMN}}\left(P=7.5 \times 10^{-5}\right.$; two-way ANOVA) mutants. Again, the two mutant strains showed practically identical phenotypes in both assay readouts tested ( $P$ values between 0.17 and 0.69 ; two-way ANOVA).

Taken together, the defective arthritis and dermatitis development in Card $^{-1-}$ mice is mostly due to the role of CARD9 within the neutrophil compartment.

Reduced neutrophil chemokine/cytokine but not $\mathrm{LTB}_{4}$ release. Given the in vivo role of CARD9 within neutrophils, we next tested various in vitro functions of $\mathrm{Card9^{-1 }}$ neutrophils. Those experiments focused on immune complex-induced activation as an in vitro model of autoantibody-induced in vivo activation.

Although $\mathrm{Card} 9^{-1-}$ neutrophils lacked the CARD9 protein (Supplementary Fig. 5a), they expressed normal levels of the neutrophil maturation marker Ly6G (Supplementary Fig. 5b), and showed normal expression of cell surface Fc $\gamma$ RII/III and Fc $\gamma$ RIV (Supplementary Fig. 5c).

CARD9 deficiency did not affect immune complex-induced short-term functional responses of neutrophils such as superoxide 

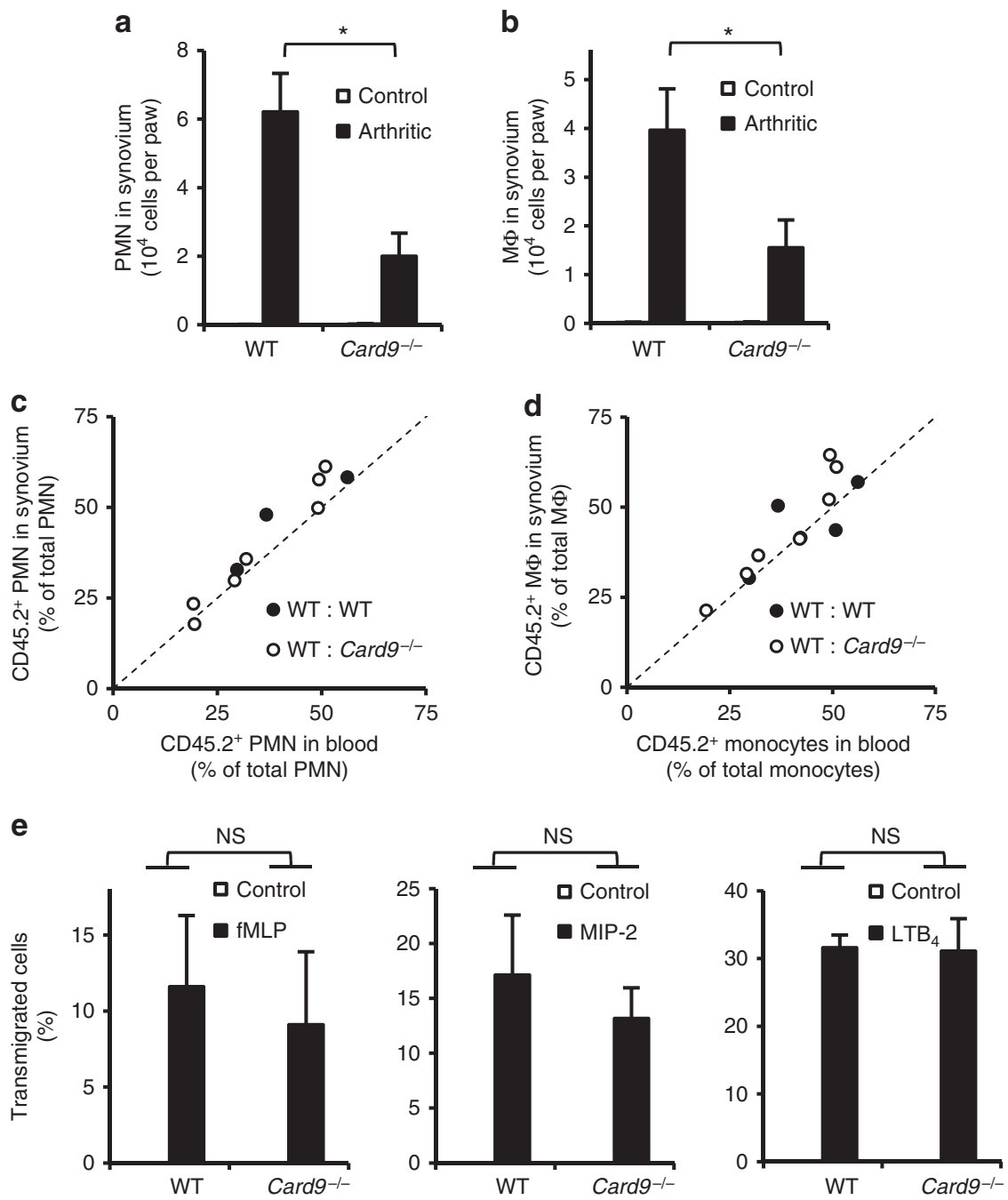

Figure 3 | CARD9 plays no direct role in myeloid cell migration to the site of inflammation. Wild type (WT) and Card $9^{-/-}$mice were subjected to $\mathrm{K} / \mathrm{B} \times \mathrm{N}$ serum-transfer arthritis (a-d), the ankle area or the front paw was flushed on day 4 and the number of neutrophils (a) or monocytes/ macrophages (b) was determined by flow cytometry. Mixed bone marrow chimeras with CD45.1-expressing wild type (WT) and CD45.2-expressing WT or Card $9^{-/-}$hematopoietic cells were subjected to $\mathrm{K} / \mathrm{B} \times \mathrm{N}$ serum-transfer arthritis and in vivo accumulation of neutrophils (c) and monocytes/ macrophages (d) was determined by flushing the synovial area on day 4, followed by flow cytometric analysis of the ratio of CD45.1 and CD45.2expressing cells in peripheral blood and the synovial infiltrate. In (c,d), each dot represents an individual mouse. (e) In vitro migration of WT and Card $9^{-/}-$ bone marrow neutrophils towards the indicated chemoattractants in a fibrinogen-coated Transwell system. Graphs represent mean and s.e.m. from 5-14 (a) or 6-16 (b) mice per group from five independent experiments. (e) Data represent mean and s.e.m. of three to five independent experiments. ${ }^{\star} P<0.05$; NS, statistically not significant (Student's $t$-test $(\mathbf{a}, \mathbf{b})$, two-way ANOVA $(\mathbf{e})$ ); see the text for actual $P$ values.

release (Fig. 6a; $P=0.79$; two-way ANOVA) or the exocytosis of gelatinase-containing granules (Fig. 6b). However, CARD9 deficiency markedly reduced the immune complex-induced release of MIP-1 $\alpha(P=0.0079$; two-way ANOVA $)$ and MIP-2 $\left(P=1.2 \times 10^{-7}\right.$; two-way ANOVA) chemokines from neutrophils (Fig. 6c). As shown in Fig. 6d, Card9 $9^{-1-}$ neutrophils also showed strong reduction of the immune complex-induced expression of the genes encoding for IL-1 $\beta$ ( $P=0.018$; two-way ANOVA), KC $\left(P=6.0 \times 10^{-16}\right.$; two-way ANOVA $)$, MIP- $1 \alpha\left(P=9.6 \times 10^{-7}\right.$; twoway ANOVA $)$ and MIP-2 $\left(P=6.2 \times 10^{-8}\right.$; two-way ANOVA).

We have also performed complementary DNA (cDNA) microarray analysis to test whether the reduced upregulation of chemokine and cytokine genes reflected a generalized defect of immune complex-induced gene expression (Fig. 6e,f; Supplementary Table 1). As shown in the heat map of the 50 most highly upregulated genes (Fig. 6e), CARD9 deficiency led to an overall decrease of immune complex-induced upregulation of neutrophil gene expression, including expression of various genes expressing pro-inflammatory mediators. The average changes of the expression of the genes shown in Fig. 6e has also been summarized in Fig. 6f, which indicated a $78 \%$ reduction of immune complex-induced gene expression in Card $9^{-1-}$ cells $\left(P<10^{-17}\right.$; two-way ANOVA).

In contrast to the various chemokines and cytokines, the immune complex-induced release of $\mathrm{LTB}_{4}$ from neutrophils was not affected by the Card $9^{-1-}$ mutation (Fig. $6 \mathrm{~g} ; P=0.39$; twoway ANOVA). In addition, the expression of Alox 5 that encodes for 5-lipoxigenase, the rate-limiting enzyme of $\mathrm{LTB}_{4}$ synthesis, is not triggered by immune complex stimulation in wild-type neutrophils ( $P=0.56$; one-way ANOVA) and it is not affected by the $\operatorname{Card}^{-I}$ mutation either (Fig. 6h). The expression of Alox5ap and Lta4h, the other two components of $\mathrm{LTB}_{4}$ synthesis, was also not altered by immune complex stimulation $(P=0.49$ and 0.64, respectively; one-way ANOVA) or CARD9 deficiency (Fig. 6i). 

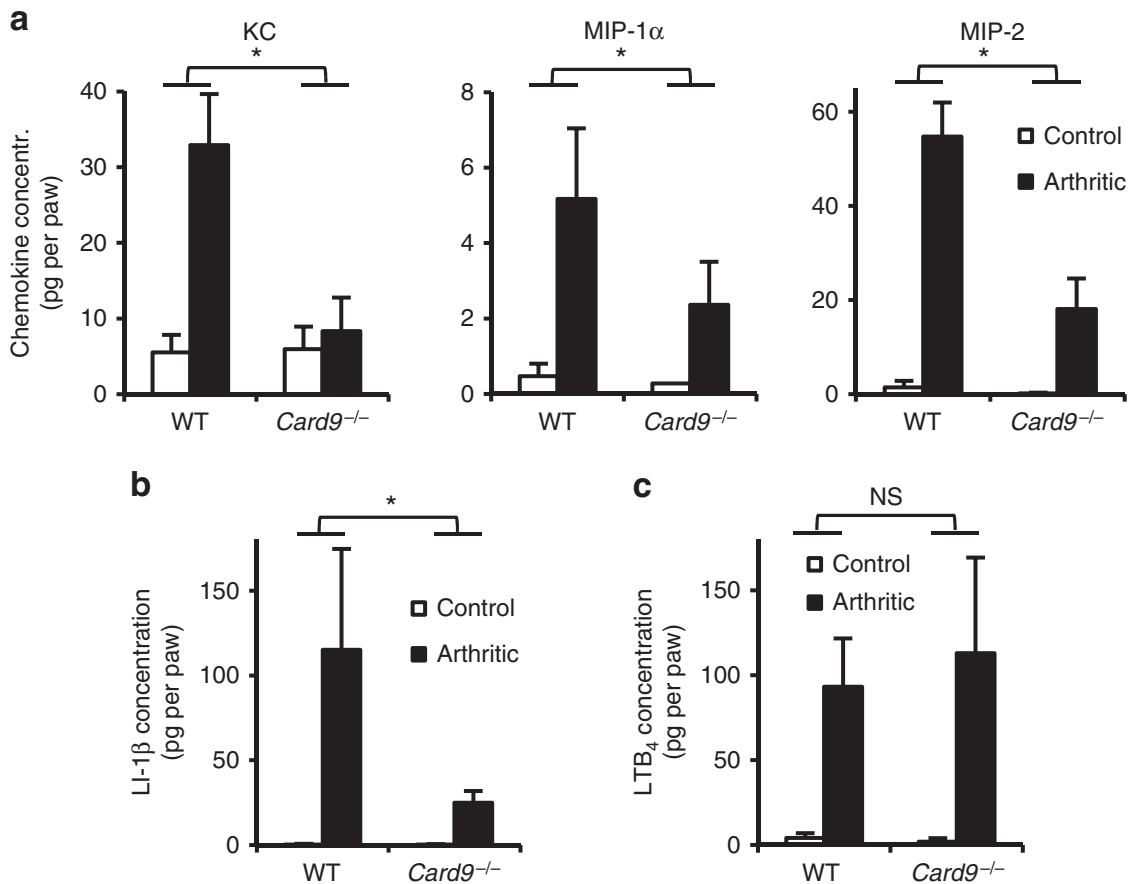

Figure 4 | CARD9 is required for the development of the inflammatory environment. (a-c) Wild type (WT) or Card9 ${ }^{-/-}$mice were subjected to $\mathrm{K} / \mathrm{B} \times \mathrm{N}$ serum-transfer arthritis as described above and the synovial area was flushed on day 4 . The cell-free supernatants of the synovial infiltrates were probed using commercial ELISA assays for the indicated chemokines (a), cytokine (b) and the lipid mediator LTB 4 (c). Graphs represent mean and s.e.m. from 4-9 (a), 3-5 (b) or 3-4 (c) mice per group from three independent experiments. ${ }^{\star} P<0.05$; NS, statistically not significant (two-way ANOVA); see the text for actual $P$ values.

Taken together, CARD9 is required for immune complexinduced gene expression changes and release of various chemokines and cytokines but not $\mathrm{LTB}_{4}$ from neutrophils. Together with the defective inflammatory response in neutrophil-specific CARD9 deletion mutants (Fig. 5), these results also provide strong evidence for the in vivo role of gene expression changes within the neutrophil compartment.

Upstream and downstream signalling components. Having established a critical role for CARD9-mediated neutrophil gene expression changes and chemokine/cytokine release, we finally aimed to characterize the signalling components upstream and downstream of CARD9 in neutrophils. We and others have previously shown that myeloid Src-family kinases (Hck, Fgr and Lyn) ${ }^{32}$, Syk $^{31,37}$ and PLC $\gamma 2$ (refs 29,30) are required for immune complexinduced neutrophil functions and the $\mathrm{K} / \mathrm{B} \times \mathrm{N}$ serum-transfer arthritis, supposedly by forming a receptor-proximal signalling cluster. We therefore compared immune complex-induced functional responses of neutrophils lacking those molecules with responses of $\mathrm{Card9}^{-1-}$ cells. As shown in Fig. 7a, Hck $\mathrm{H}^{-1-}$ $\mathrm{Fgr}^{-1-} \mathrm{Lyn}^{-1-}(3 \times$ SFK KO $), \quad$ Syk ${ }^{-1-}$ and $\mathrm{Plcg}^{-1-}$ neutrophils showed complete defect in immune complex-induced superoxide production $\left(P\right.$ values between $7.9 \times 10^{-5}$ and $1.6 \times 10^{-4}$; two-way ANOVA), whereas $\operatorname{Card9^{-1}}$ cell showed a normal response $(P=0.73$; two-way ANOVA). Similarly, as shown in Fig. 7b,c, while $\mathrm{Hck}^{-1-} \mathrm{Fgr}^{-1-} \mathrm{Lyn}^{-1-}, \mathrm{Syk}^{-1-}$ and Plcg2 ${ }^{-1-}$ neutrophils showed complete defect in immune complex-induced MIP-2 and $\mathrm{LTB}_{4}$ release $\left(P\right.$ values between $2.9 \times 10^{-4}$ and $9.4 \times 10^{-3}$; two-way ANOVA), Card $9^{-1}-$ neutrophils displayed a strong but incomplete reduction of MIP-2 release $(P=0.027$; twoway ANOVA) and no significant reduction of $\mathrm{LTB}_{4}$ release $\left(P=0.38\right.$; two-way ANOVA). The $\mathrm{Card}^{-1-}$ neutrophil phenotype was not due to defective receptor-proximal signalling since $\operatorname{Card} 9^{-1-}$ neutrophils showed normal Syk phosphorylation on activation by immobilized immune complexes (Fig. 7d). Those results suggest that CARD9 functions downstream of the receptorproximal Src-family/Syk/PLC $\gamma 2$ complex during immune complexinduced neutrophil activation.

During fungal infection, CARD9 coordinates anti-fungal host defence in cooperation with the downstream adapter Bcl10 (ref. 7). Therefore, we tested neutrophil functions and arthritis development in the absence of Bcl10. $B c l 10^{-1-}$ neutrophils lacked the Bcl10 protein (Supplementary Fig. 6a) but expressed normal levels of Ly6G (Supplementary Fig. 6b) and Fc $\gamma$-receptors (Supplementary Fig. 6c). On immune complex challenge, $\mathrm{Bcl10}^{-1-}$ neutrophils showed normal superoxide release (Fig. 7e; $P=0.76$; two-way ANOVA) but defective release of the MIP-2 chemokine (Fig. 7f; $P=0.0057$; two-way ANOVA). As shown in Supplementary Fig. 7, the $\mathrm{BcllO}^{-1-}$ mutation also caused partial protection from the clinical signs $(P=0.065$; twoway ANOVA) and ankle-thickening response $(P=0.015$; twoway ANOVA) during $\mathrm{K} / \mathrm{B} \times \mathrm{N}$ serum-transfer arthritis. The CARD9-Bcl10 complex is thought to signal through the Malt1 paracaspase during antifungal immunity ${ }^{f}$. As shown in Fig. $7 g, h$, Malt $1^{-1-}$ neutrophils produced normal levels of superoxide on immune complex activation $(P=0.87$; two-way ANOVA) but their MIP-2 release was substantially reduced under identical conditions $(P=0.0092$; two-way ANOVA). The similarity

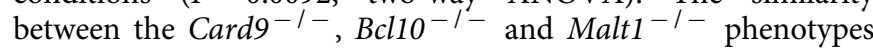
suggests that $\mathrm{Bcl} 10$ and Malt1 participates in signalling downstream of CARD9 during immune complex-induced neutrophil activation.

We have also explored how CARD9 is coupled to upregulation of pro-inflammatory gene expression. CARD9 deficiency strongly reduced immune complex-induced phosphorylation and

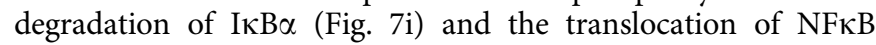


a

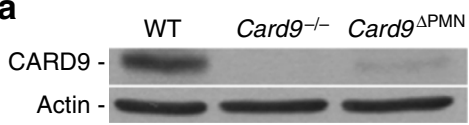

C

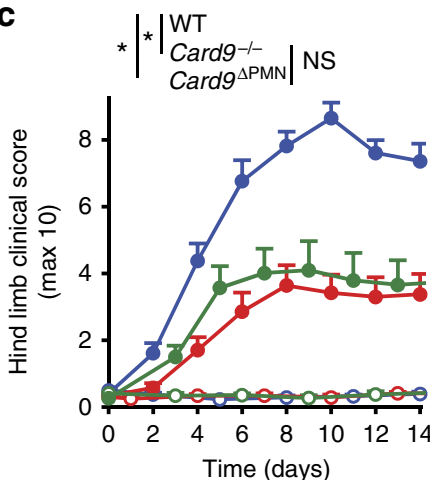

e

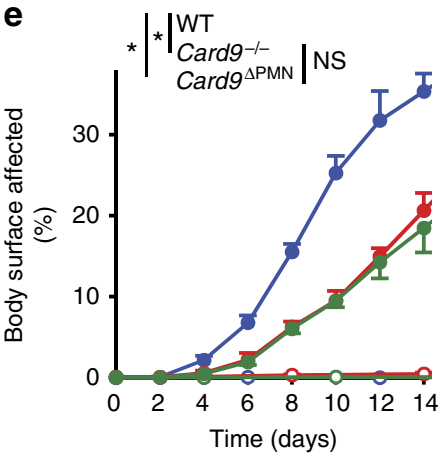

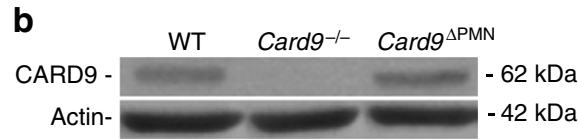

d
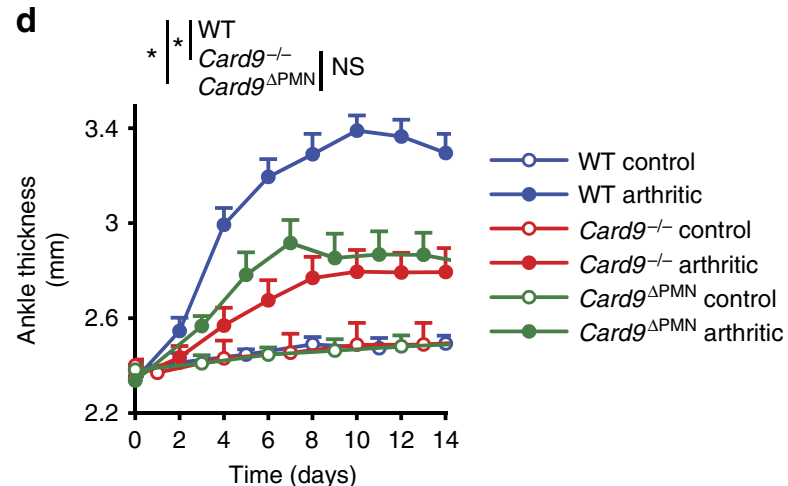

f

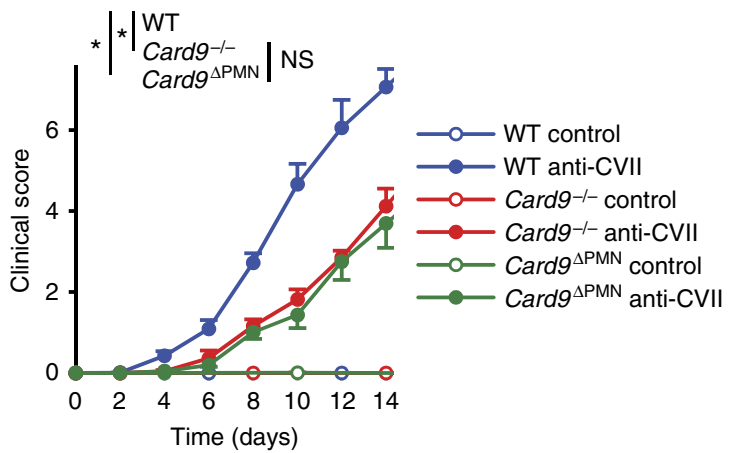

Figure 5 | Neutrophil-specific CARD9 deletion attenuates autoantibody-induced inflammation. (a,b) CARD9 expression was detected by western blot in cell-sorted bone marrow-derived neutrophils (a) or cultured macrophages (b) of wild type, Card9-/ - or Card9 ${ }^{\Delta \mathrm{PMN}}$ animals. (c,d) Wild type (WT), Card9 ${ }^{-/}$- or Card $9^{\triangle P M N}$ bone marrow chimeras were injected with $\mathrm{B} \times \mathrm{N}$ (control) or $\mathrm{K} / \mathrm{B} \times \mathrm{N}$ (arthritic) serum i.p. on day 0 . Arthritis development was followed by clinical scoring of the hind limbs (c) and ankle-thickness measurement (d). Blistering skin disease was triggered in wild type (WT), Card $9^{-/-}$ or Card $9^{\triangle \mathrm{PMN}}$ intact mice or bone marrow chimeras by systemic injection of collagen VII-specific (anti-CVII) antibodies. Skin disease was followed by clinical assessment of the total body surface affected (e) and the overall disease severity (f). The blots are representative of three to four independent experiments. Quantitative data show mean and s.e.m. from 7 control and 8 to 9 arthritic serum-treated individual mice per group from three independent experiments $(\mathbf{c}, \mathbf{d})$ or 3 to 4 control and 4 anti-CVII-treated mice per group from two independent experiments $(\mathbf{e}, \mathbf{f})$. ${ }^{\star} P<0.05$ (two-way ANOVA); NS, not significant; see the text for actual $P$ values.

p65 to the nucleus (Fig. 7j), indicating that CARD9 triggers upregulation of inflammatory gene expression through activation of the canonical NFKB pathway.

Taken together, the CARD9 signalling pathway responsible for chemokine/cytokine production by neutrophils during inflammation in vivo is reminiscent of the signalling pathway utilized by C-type lectin receptors and consists of a receptor-proximal Src-family/Syk/PLC $\gamma 2$ module triggering $\mathrm{NF} \kappa \mathrm{B}$ activation through the CARD9/Bcl10/Malt1 complex.

\section{Discussion}

Our results indicate that the CARD9 protein expressed within the neutrophil compartment plays an important role in chemokine and cytokine but not $\mathrm{LTB}_{4}$ release during autoantibody-induced sterile inflammation. To our knowledge, these are the first experiments showing that neutrophil-specific abrogation of agonist-induced gene expression changes (without affecting other neutrophil functions) inhibits in vivo inflammatory reactions and therefore provide the most direct evidence so far for an important in vivo role of inflammation-induced gene expression changes within the neutrophil lineage.
Although neutrophils have long been known to be critical effector cells of antimicrobial host defence, more recent studies indicated that they are also capable of releasing pro-inflammatory mediators 5,6 . Unfortunately, direct evidence for the role of neutrophil gene expression or neutrophil-derived chemokines/ cytokines has been missing. A number of prior studies reported a critical role for neutrophils in in vivo inflammatory reactions ${ }^{2,28}$ and a recent study has shown that neutrophil-specific deletion of Syk blocked arthritis development in the K/B $\times \mathrm{N}$ serum-transfer model $^{37}$. Unfortunately, since those approaches not only blocked neutrophil-derived gene expression but also other functional responses of those cells, the specific effect of gene expression changes could not be assessed. Other attempts utilized complementation approaches using mixed bone marrow chimeras or isolated bone marrow neutrophils ${ }^{27,38,39}$ Unfortunately, all those approaches had major limitations related to the limited specificity of the $G f i 1^{-/-}$strain used or the limited purity and altered activation status of ex vivo isolated bone marrow-derived neutrophils. Our results with the $\operatorname{Card} 9^{\Delta \mathrm{PMN}}$ mutants (Fig. 5) provide the first direct evidence using lineage-specific deletion that the products of neutrophil gene expression coordinate the in vivo inflammatory response without affecting conventional neutrophil functions such as reactive 
a
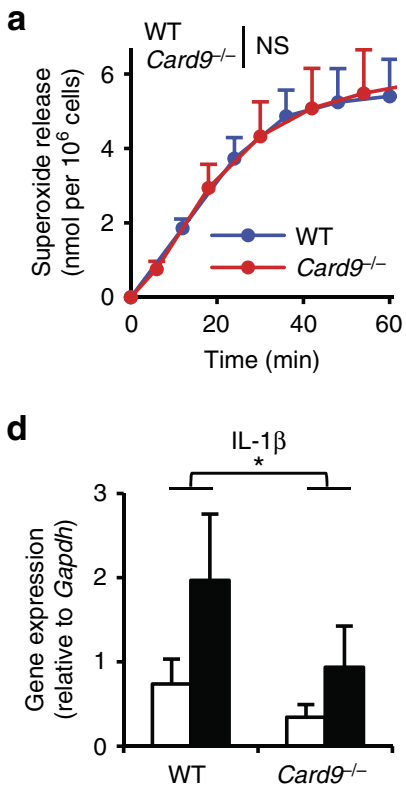

e
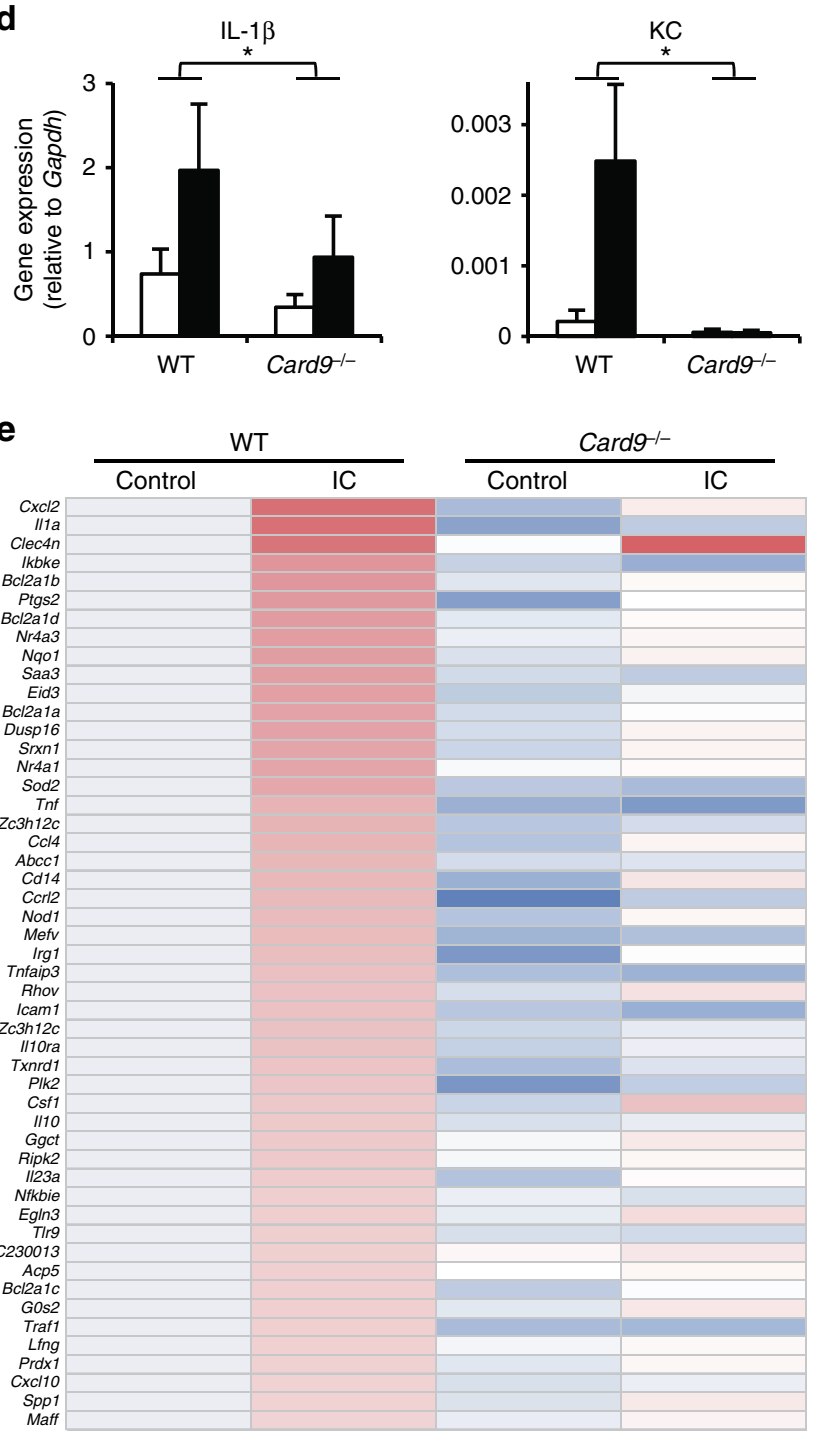

b

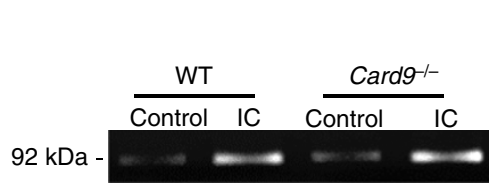

C

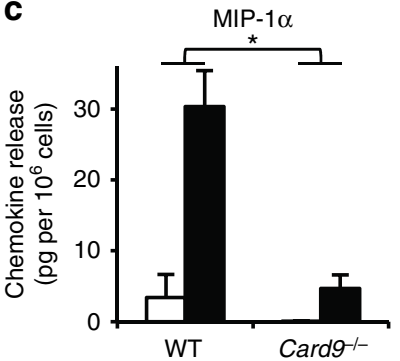

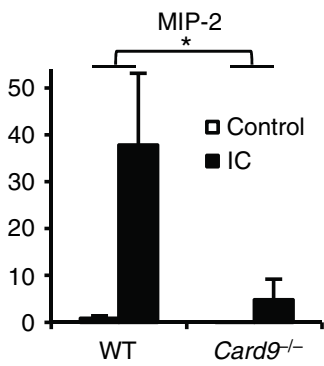
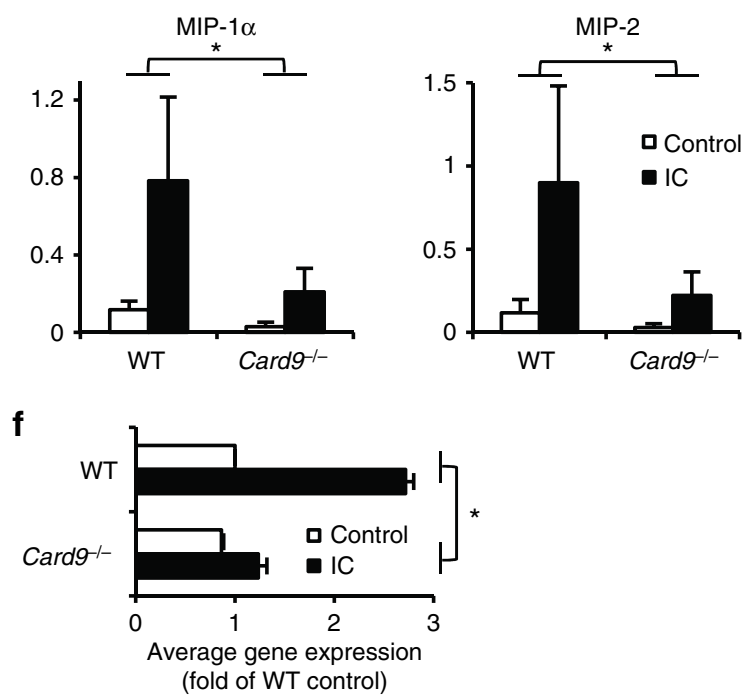

g

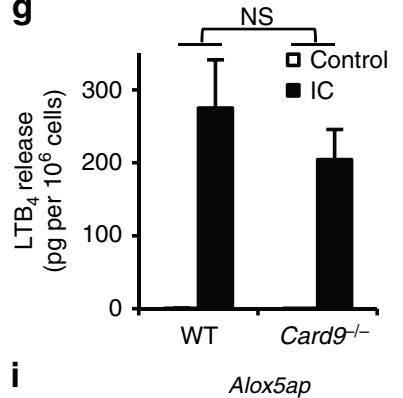

h
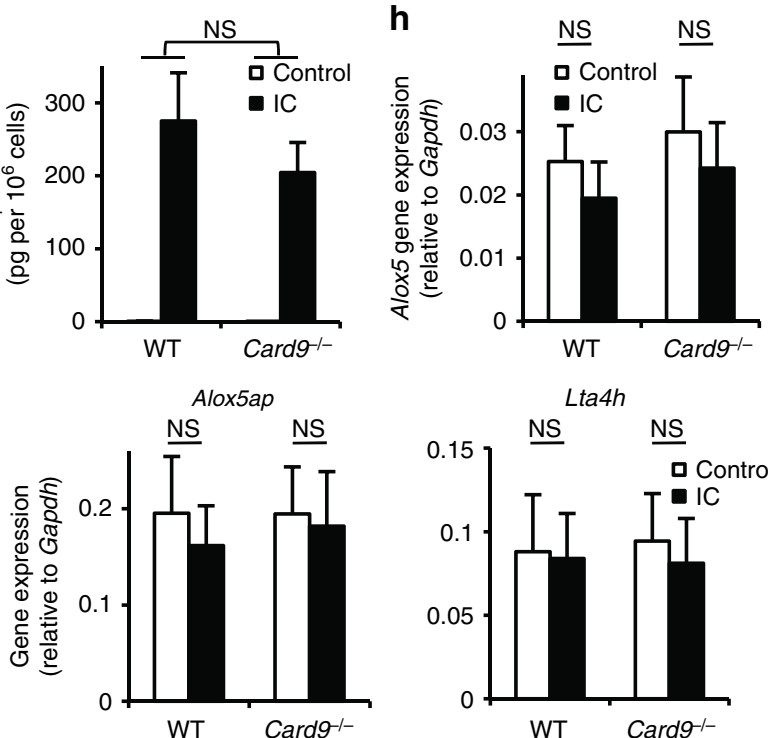

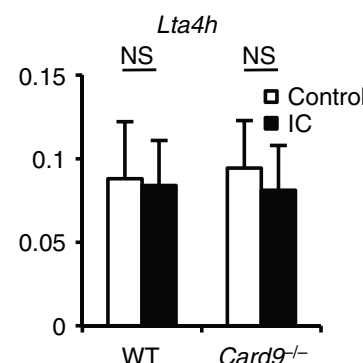

Figure 6 | CARD9 is required for neutrophil gene expression changes and chemokine/cytokine release. Wild type (WT) and Card9-/ ${ }^{-}$neutrophils were placed on immobilized immune complex (IC) surfaces. Superoxide release (a) was followed by a spectrophotometric assay, while gelatinase degranulation was determined by gelatinase zymography (b). Cytokine, chemokine and lipid mediator levels in cell-free supernatants were determined after an incubation for $6 \mathrm{~h}$ (cytokines) or $1 \mathrm{~h}\left(\mathrm{LTB}_{4}\right)$ using ELISA assays $(\mathbf{c}, \mathbf{g})$. Gene expression changes were followed by quantitative PCR $(\mathbf{d}, \mathbf{h}, \mathbf{i})$ or by Affymetrix Microarrays (e,f). (f) The average changes of the expression of the 50 most highly upregulated genes shown in (e). Kinetic curves in a show mean and s.e.m. of six independent experiments. Control data points were subtracted. (b) Representative of three independent experiments. Graphs (c,d,fi) show mean and s.e.m. from three to five independent experiments, while the heat map in e represents the colour-coded mean of three independent experiments. ${ }^{\star} P<0.05$; NS, statistically not significant (two-way ANOVA except for $\mathbf{h}$ and $\mathbf{i}$ where one-way ANOVA was used); see the text for actual $P$ values.

oxygen species (ROS) release. Our overall study also suggests that neutrophil-derived $\mathrm{LTB}_{4}$ is capable of driving a clinically evident, though substantially reduced level of neutrophil-mediated inflammation even in the absence of neutrophil-derived chemokines and cytokines. Those results together provide substantial novel insight into the in vivo role of neutrophil gene 
a

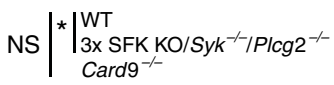

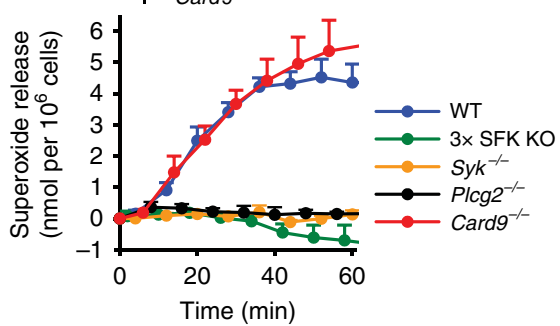

d

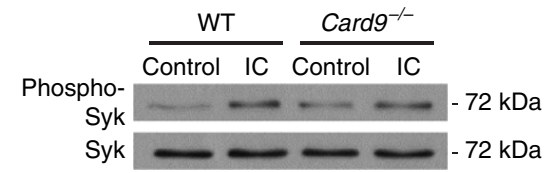

b

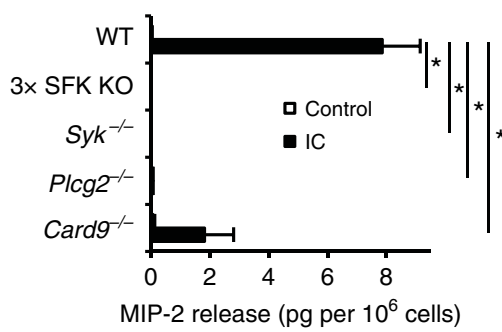

C

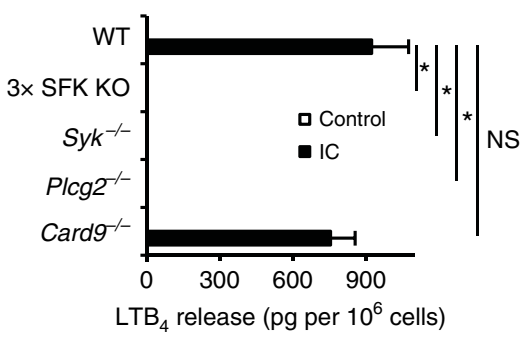

e

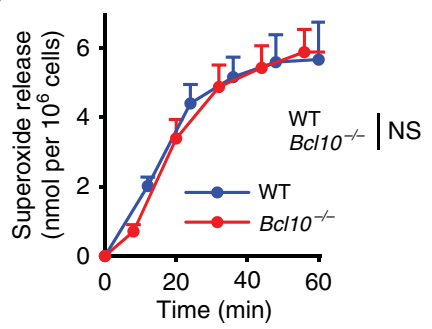

f

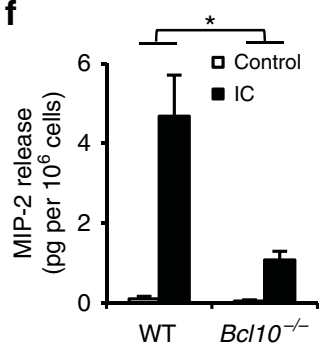

g

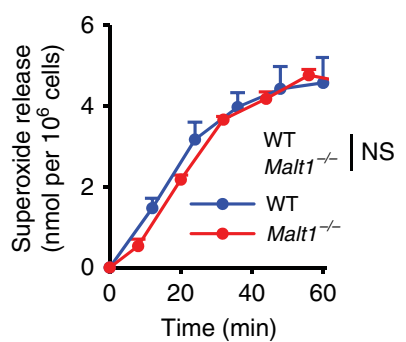

h

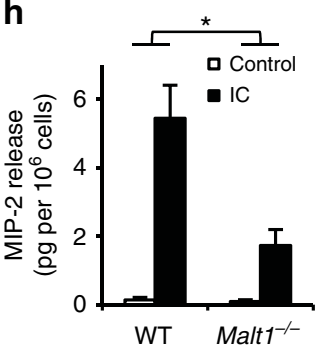

i

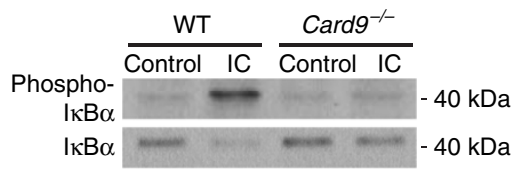

j

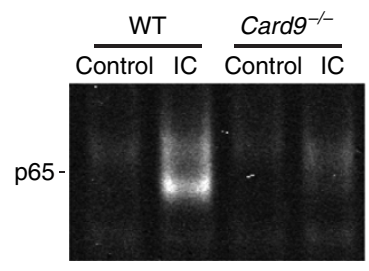

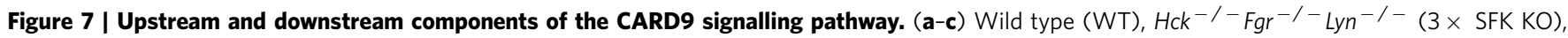

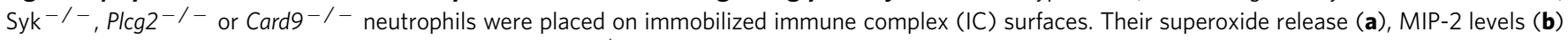

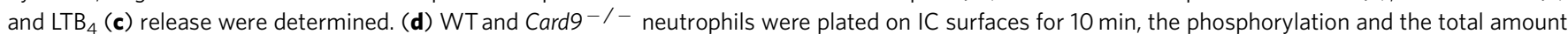
of Syk in cell lysates was determined by western blot after immunoprecipitation. (e-h) Bcl10 ${ }^{-/-}$and Malt1 ${ }^{-/-}$neutrophils showed similar functional phenotypes on IC surfaces like Card9-/ - neutrophils: they had intact superoxide release (e,g) and defective chemokine production (f,h). (i) WT and Card $9^{-/-}$neutrophils were stimulated for 20 min; the phosphorylation and degradation of I $\mathrm{K} \alpha$ was followed by western blotting from whole cell lysates. (j) IC-activated WT and Card9 ${ }^{-/-}$neutrophils were lysed after 20 min; the activation and nuclear translocation of NF- $\kappa B$ was determined by infrared dyelabelled NFKB consensus binding site probes. Kinetic curves in $\mathbf{a}, \mathbf{e}$ and $\mathbf{g}$ show mean and s.e.m. of three to four independent experiments. Control data points were subtracted. Graphs in $\mathbf{b}, \mathbf{c}, \mathbf{f}$ and $\mathbf{h}$ represent data from two to four independent experiments. (d,i,j) Representative of two to three independent experiments. ${ }^{\star} P<0.05$; NS, statistically not significant (two-way ANOVA); see the text for actual $P$ values.

expression and neutrophil-derived mediators during the inflammatory response.

The role of CARD9 has so far mainly been tested in functional responses of dendritic cells and macrophages, myeloid cell types primarily implicated in the organization of an adaptive immune response. Though we have observed that $\operatorname{Card9^{-1}}$ macrophages also show defective chemokine but not ROS release (Supplementary Fig. 8), our lineage-specific studies indicate that, at least in our experimental system, the effect of CARD9 deficiency is primarily due to the CARD9 expression in neutrophils. This is further supported by the presence of normal levels of CARD9 in Card $9^{\triangle \mathrm{PMN}}$ macrophages.

A crucial question related to the interpretation of our lineagespecific deletion studies is the specificity of the MRP8-Cre transgene. The MRP8 (S100A8) protein is also expressed in other myeloid cells such as macrophages, and therefore Cre-mediated deletion of target genes could have been predicted also in macrophages. However, the fact that CARD9 is expressed normally in $\operatorname{Card} 9^{\triangle \mathrm{PMN}}$ bone marrow-derived (Fig. $5 \mathrm{~b}$ ) macrophages indicates that this is not the case. Indeed, the original description of the MRP8-Cre transgene ${ }^{35}$ indicated high specificity towards neutrophils and detailed recent studies have also shown negligible deletion of floxed genomic sequences in MRP8-Cre transgene-positive macrophages or dendritic cells ${ }^{36,37}$. This high specificity may be due to the fact that MRP8 is likely the most abundant cytoplasmic protein in neutrophils and the ImmGen database ${ }^{23}$ indicates that it is expressed at $20-100$-fold higher levels in neutrophils than in any other myeloid lineage cell types. Those results together provide convincing evidence that the in vivo phenotypes of the Card $9^{\triangle \mathrm{PMN}}$ mutants are due to specific deletion of CARD9 from the neutrophil lineage.

Although the role of CARD9 in antifungal and other antimicrobial immunity is well established ${ }^{7}$, its role in noninfectious inflammation is poorly understood. The protection of $\operatorname{Card}^{-1}$ mice from autoantibody-induced inflammatory reactions and the defective responses of $\operatorname{Card}^{-1}$ - cells to immune complex stimulation indicate a critical role for CARD9 also in non-infectious inflammatory processes. This issue is particularly important given the association of CARD9 polymorphisms with rheumatoid arthritis, inflammatory bowel 
disease, ankylosing spondylitis or IgA nephropathy ${ }^{14-21}$, major human inflammatory diseases of non-infectious origin. IgA nephropathy, the most frequent form of primary glomerulonephritis in humans, is particularly interesting since it is caused by immune complex deposition at the glomerular basement membrane $e^{40}$. As neutrophils are the primary cell types responding to systemic IgA through the human-specific Fc $\alpha$ RI (CD89) molecule ${ }^{41}$, it is tempting to speculate that, similar to our studies in mice, the potential role of CARD9 in IgA nephropathy is due to its role in immune complex-induced neutrophil activation.

Autoantibody-induced inflammation has been shown to be mediated by a lipid-cytokine-chemokine cascade ${ }^{27}$, which also triggers autoamplification of leucocyte recruitment ${ }^{42}$. We and others have previously shown that a receptor-proximal Src-family/Syk/PLC 2 signalling module is critical for autoantibody-induced arthritis and dermatitis ${ }^{29-32,37,43}$. However, it has been unclear how that signalling module is coupled to chemokine, cytokine and lipid mediator release. Our results indicate that CARD9 acts as a divergence point downstream of the receptor-proximal Src-family/Syk/PLC $\gamma 2$ module in neutrophils and leads to Bcl10/Malt1- and NFKB-dependent chemokine and cytokine release without playing a role in lipid mediator $\left(\mathrm{LTB}_{4}\right)$ production (Supplementary Fig. 9). Those results reveal intricate details of myeloid cell signalling during autoantibody-induced inflammation. The normal $\mathrm{LTB}_{4}$ release also likely explains why Card $9^{-1-}$ animals are only partially protected from arthritis and dermatitis development.

Though it is not entirely clear how the CARD9-Bcl10-Malt1 complex activates the NFKB pathway, the mechanism of activation and nuclear translocation of NFKB by the CARD9related CARMA-like proteins has been investigated in other immune cells. Assembly of CARMA proteins with Bcl10 and Malt1 leads to the ubiquitination of the regulatory $I \kappa B \alpha$ kinase subunit NEMO and the phosphorylation and degradation of $\mathrm{I} \kappa \mathrm{B} \alpha($ ref 44$)$. CARMA-like proteins supposedly exert their effect through binding to TRAF6 and recruiting TAK1 to the CARMABcl10-Malt1 complex, where TAK1 activates IKK leading to the above-mentioned $I \kappa B \alpha$ phosphorylation ${ }^{45}$. Furthermore, activated Malt1 inactivates the negative regulator of $\mathrm{NF \kappa B}$ signalling ${ }^{7}$.

Taken together, our experiments reported here provide substantial novel insight and mechanistic detail about various aspects of the inflammatory reaction, including (1) the in vivo role of neutrophil gene expression and chemokine/cytokine release; (2) the contribution of CARD9 to non-infectious inflammation and (3) the pathways coupling immunoreceptors to cellular effector functions (Supplementary Fig. 9). Those results will improve our understanding of the pathomechanism of autoimmune and inflammatory diseases and may contribute to the development of novel diagnostic and therapeutic strategies in the future.

\section{Methods}

Animals. Mice homozygous for the Card $9^{\mathrm{tm} 1 \text { Jrld }}, B c l 10^{\mathrm{tm} 1 \mathrm{Mak}}$, Malt $1^{\mathrm{tm} 1 \mathrm{Jrld}}$ or Plcg2 ${ }^{\mathrm{tm} 1 \mathrm{JnI}}$ mutations (referred to as Card9 $9^{-/-}, \mathrm{BcllO}^{-/-}, \mathrm{Malt}^{-1-}$ and Plcg2 ${ }^{-1-}$ mutants, respectively) or triple homozygous for the $H c k^{\mathrm{tm} 1 \mathrm{Hev}}$, $\mathrm{Fgr}^{\mathrm{tm} 1 \mathrm{Hev}}$ and $\mathrm{Lyn} \mathrm{tm}^{\mathrm{tm} \text { iSo }}$ mutations (referred to as $\mathrm{Hck}^{-l-} \mathrm{Fgr}^{-1-} \mathrm{Lyn}^{-1-}$ or $3 \times$ SFK KO mice) were described previously ${ }^{8,46-49}$. Heterozygous mice carrying a deleted Syk allele $\left(S y k^{\mathrm{tm} 1 \mathrm{Tyb}}\right.$, referred to as $\left.S y k^{-}\right)$were time-mated and their embryos were used to generate bone marrow chimeras with a $S y k^{-1-}$ hematopoietic system as described ${ }^{31}$. Mice homozygous for the Card $9^{\text {tmla(EUCOMM)Hmgu }}$ knockout-first mutation ${ }^{33}$ (referred to as Card $9^{-1-}$ (EUCOMM) mice) were obtained from the Wellcome Trust Sanger Institute (EUCOMM Project No. 44813). Mice carrying the Card $9^{\text {tmla(EUCOMM)Hmgu }}$ knockout-first mutation were also bred to the FLPeR deleter strain ${ }^{50}$ to remove the FRT-flanked knockout-first cassette generating the Card $9^{\text {tmlc(EUCOMM)Hmgu }}$ floxed allele (referred to as Card $9^{\text {flox }}$ ), followed by breeding to the MRP8-Cre transgenic mice ${ }^{35}$ to generate MRP8-Cre ${ }^{+} \mathrm{Card}^{\text {flox/flox }}$ (referred to as Card $9^{\triangle \mathrm{PMN}}$ ) mice with a neutrophil-specific CARD9 deletion. Mice carrying the KRN T-cell-receptor transgene ${ }^{51}$ were obtained from Diane Mathis and Christophe Benoist (Harvard Medical School) and maintained in heterozygous form by mating with $\mathrm{C} 57 \mathrm{BL} / 6$ mice.

All transgenic mice were backcrossed to the $\mathrm{C} 57 \mathrm{BL} / 6$ genetic background for at least six generations. Genotyping was performed by allele-specific PCR.

Wild-type control C57BL/6 mice were purchased from Charles River or the Hungarian National Institute of Oncology (Budapest, Hungary). NOD mice, as well as a congenic strain carrying the CD45.1 allele on the C57BL/6 genetic background (B6.SJL-Ptprc ${ }^{\mathrm{a}}$ ) were purchased from the Jackson Laboratory.

Mice were kept in individually sterile ventilated cages (Tecniplast) in a conventional facility. All animal experiments were approved by the Animal Experimentation Review Board of the Semmelweis University.

Bone marrow chimeras were generated by intravenous injection of bone marrow cells into recipients carrying the CD45.1 allele on the C57BL/6 genetic background, which were lethally irradiated before by $11 \mathrm{~Gy}$ from a ${ }^{137} \mathrm{Cs}$ source using a Gamma-Service Medical (Leipzig, Germany) D1 irradiator. Four weeks after transplantation, peripheral blood samples were stained for Ly6G and CD45.2 (at a final concentration of $2 \mu \mathrm{g} \mathrm{ml}^{-1}$ ) and analysed by flow cytometry as previously described ${ }^{32}$.

Mice of both genders at 2-6 months of age were used for the experiments.

$\mathbf{K} / \mathbf{B} \times \mathbf{N}$ serum-transfer arthritis. Mice carrying the KRN T-cell receptor transgene on the $\mathrm{C} 57 \mathrm{BL} / 6$ genetic background were mated with NOD mice to obtain transgene-positive (arthritic) $\mathrm{K} / \mathrm{B} \times \mathrm{N}$ and transgene-negative (non-arthritic) $\mathrm{B} \times \mathrm{N}$ mice ${ }^{30,51}$. The presence of the transgene was determined by allele-specific PCR and confirmed by phenotypic assessment. Blood was taken by retroorbital bleeding and sera from arthritic and control mice were pooled separately.

Arthritis was induced by a single intraperitoneal injection of $300 \mu \mathrm{K} / \mathrm{B} \times \mathrm{N}$ (arthritic) or $\mathrm{B} \times \mathrm{N}$ (control) serum into intact mice or bone marrow chimeras, followed by daily assessment of arthritis severity for 2 weeks as described ${ }^{30}$. Visible clinical signs were scored on a $0-10$ scale by two investigators blinded for the origin and treatment of the mice. Ankle thickness was measured by a spring-loaded caliper (Kroeplin).

To investigate serum-induced articular dysfunction, mice were placed on a custom-made (Charles River Hungary, Isaszeg, Hungary) wire grid, slowly flipped and the length of time the mice held on to the grid was recorded as described ${ }^{30}$. The obtained data were combined into 'holding-on curves' for each mouse.

Autoantibody-induced skin blistering model. The murine model of the human blistering skin disease epidermolysis bullosa acquisita was triggered by systemic administration of antibodies against collagen type VII(ref 25). The bacterial expression of GST fusion proteins containing the mCVIICr fragment of mouse collagen VII, its purification, the generation of polyclonal antiserum in rabbits and IgG fraction separation were carried out as previously described ${ }^{25,52}$. The reactivity of the antibody preparation was tested with His-tagged mCVIICr fragment of murine collagen VII using an enzyme-linked immunosorbent assay (ELISA) as described $^{52}$. Normal rabbit IgG (Sigma) or PBS was used as control.

Twelve milligrams of pathogenic or control IgG per mouse was injected subcutaneously under isoflurane anaesthesia on days $0,2,4,6$ and 8 (60 mg total $\mathrm{IgG} / \mathrm{mouse})$. The disease onset and progression was followed by clinical assessment every second day. Scoring was based on the specific dermatological abnormalities (for example, erythema, blister, crust) and the size of the affected skin area, the latter one determined by using predefined percentages of the various areas of the skin of mice (for example, one ear: $2.5 \%$; snout: $5 \%$ and so on). Antibody levels against collagen VII in blood samples at day 6 were determined by ELISA.

In vivo analysis of myeloid cell migration. In case of the $\mathrm{K} / \mathrm{B} \times \mathrm{N}$ serum-transfer model, the ankle or front paw area was flushed with $1 \mathrm{ml}$ PBS supplemented with $10 \mathrm{mM}$ EDTA ( $\mathrm{pH} 7.5$ ) and $20 \mathrm{mM}$ HEPES (pH 7.4; Sigma) on day 4 to obtain a sample of synovial infiltrate. The number and distribution of the myeloid cells in the resulting suspension was then determined by flow cytometry. Cells were identified based on their forward- and side-scatter characteristics, as well as by positive staining of neutrophils for Ly6G (clone 1A8 from BD Biosciences; final concentration: $2 \mu \mathrm{g} \mathrm{ml}^{-1}$ ), or positive staining of monocytes/macrophages for F4/80 (Clone: A3-1, AbD Serotec; final concentration: $10 \mu \mathrm{g} \mathrm{ml}^{-1}$ ) or CD11b (Clone: M1/70, BD Biosciences; final concentration: $2 \mu \mathrm{g} \mathrm{ml}^{-1}$ ) within the Ly6G-negative gate.

A competitive migration assay in mixed bone marrow chimeras ${ }^{30}$ was also used to assess in vivo migration of myeloid cells. To this end, wild type (C57BL/6) or Card $9^{-1-}$ bone marrow cells (all carrying the CD45.2 allele) were mixed at varying ratios with bone marrow cells from congenic mice expressing CD45.1 on the C57BL/6 genetic background. This mixed cell suspension was injected intravenously into lethally irradiated CD45.1-expressing recipient mice, giving rise to mixed bone marrow chimeras carrying CD45.2-expressing wild type or Card $9^{-1-}$ along with CD45.1-expressing wild type hematopoietic cells within the same animals. After the repopulation of the bone marrow, the chimeras were 
subjected to $\mathrm{K} / \mathrm{B} \times \mathrm{N}$ serum-transfer arthritis and their synovial infiltrates were prepared as described above. The percentage of CD45.2-expressing cells were analysed by flow cytometry as described above, with an additional staining for CD45.2 (Clone: 104, BD Biosciences; final concentration: $2 \mu \mathrm{g} \mathrm{ml}^{-1}$ ).

Relative migration (accumulation) of the CD45.2-positive neutrophils or monocytes/macrophages (relative to the CD45.1-expressing wild-type cells) was calculated as described ${ }^{32}$.

Isolation and activation of neutrophils and macrophages. Mouse neutrophils were isolated from the bone marrow of the femurs and tibias of intact mice or chimeras by hypotonic lysis followed by Percoll (GE Healthcare) gradient centrifugation using sterile and endotoxin-free reagents as described ${ }^{53}$. Cells were kept at room temperature in $\mathrm{Ca}^{2+}$ - and $\mathrm{Mg}^{2+}$-free medium until use and prewarmed to $37^{\circ} \mathrm{C}$ prior to activation. Neutrophil assays were performed at $37^{\circ} \mathrm{C}$ in Hanks' Balanced Salt Solution (HBSS) supplemented with $20 \mathrm{mM}$ HEPES, pH 7.4. Neutrophil cell surface Fc $\gamma$ receptor expression was detected by anti-Fc $\gamma$ RII/III (Clone: 2.4G2, BD Biosciences; final concentration: $2 \mu \mathrm{g} \mathrm{ml}^{-1}$ ) and anti-Fc $\gamma \mathrm{RIV}$ antibodies (final concentration: $10.2 \mu \mathrm{g} \mathrm{ml}^{-1}$ ), followed by a secondary staining with fluorochrome-conjugated Mouse anti-rat and Mouse anti-hamster antibodies (Clones: MRK-1 and G70-204/G94-56, respectively, both from BD Biosciences; final concentration: $1 \mu \mathrm{g} \mathrm{ml}^{-1}$ ).

Mouse bone marrow-derived macrophages were obtained by culturing bone marrow cells from intact mice in $\alpha$-MEM (Sigma) complemented with $10 \%$ FCS (Invitrogen), $2 \mathrm{mM}$ L-glutamine, antibiotics, $10 \mathrm{mM}$ HEPES (all from Sigma) and $10 \%$ conditioned medium from CMG 14-12 cells as a source of recombinant murine M-CSF ${ }^{54}$ for 8 days on bacterial Petri dishes with media changes every 2-3 days. Cells were suspended by $5 \mathrm{mM}$ EDTA, washed and serum-starved for $2 \mathrm{~h}$ before the experiments.

To obtain immobilized immune complex-coated surfaces, human serum albumin (Sigma) or lactoferrin (Sigma) was either bound directly to regular or luminometric Nunc MaxiSorp F96 (Thermo Fisher) plates or covalently linked to poly-L-lysine-coated 24-well tissue culture plates or 6-cm tissue culture dishes and then treated with anti-human serum albumin or anti-lactoferrin IgG (Sigma) as described $^{55}$.

For the analysis of cytokine release, 100 or $500 \mu \mathrm{l}$ aliquots of $4 \times 10^{6}$ per ml neutrophils or $500 \mu \mathrm{l}$ aliquots of $3 \times 10^{6}$ per ml macrophages suspended in HBSS supplemented with $20 \mathrm{mM}$ HEPES, pH 7.4 were plated on immobilized immune complex surfaces in 96-well ELISA plates or 24-well tissue culture plates, stimulated for $6 \mathrm{~h}$ (neutrophils) or $24 \mathrm{~h}$ (macrophages) and the inflammatory mediator concentration of the supernatant was determined. For the analysis of $\mathrm{LTB}_{4}$ production, $100 \mu \mathrm{l}$ aliquots of $4 \times 10^{6}$ per ml neutrophils suspended in DMEM (Sigma) were plated on immobilized immune complex surfaces in 96-well ELISA plates for $1 \mathrm{~h}$ and the $\mathrm{LTB}_{4}$ concentration of the cell-free supernatant was measured. Superoxide release by neutrophils was followed by a cytochrome $\mathrm{c}$ reduction test from $100 \mu \mathrm{l}$ aliquots of $4 \times 10^{6}$ per ml cells plated on immune complex-coated surfaces in 96 -well ELISA plates as described ${ }^{56}$. To test ROS production by macrophages, $100 \mu \mathrm{l}$ aliquots of $3 \times 10^{6}$ per ml cells were plated on immune complex-coated surfaces in 96-well luminometric ELISA plates in the presence of $50 \mu \mathrm{g} \mathrm{ml}^{-1}$ lucigenin (Sigma) and the chemiluminescence of the samples was followed by a Berthold (Bad Wildbad, Germany) Mithras LB 940 luminometer. The release of gelatinase was determined by gelatinase zymography as previously described ${ }^{56}$

In vitro migration of neutrophils was tested by using a Transwell (Corning) assay with inserts of $3 \mu \mathrm{m}$ pore size coated with human fibrinogen as described ${ }^{30}$. Three microlitres of fMLP (Sigma), $100 \mathrm{ng} \mathrm{ml}^{-1}$ MIP-2 (Peprotech) or $50 \mathrm{ng} \mathrm{ml}^{-1}$ $\mathrm{LTB}_{4}$ (Santa Cruz Biotechnology) was used as chemoattractants. Transmigrated cells were measured by an acid phosphatase assay ${ }^{30}$.

Analysis of inflammatory mediators. The release of inflammatory mediators was tested from the cell-free supernatants of synovial infiltrates gathered on day 4 or of in vitro stimulated neutrophils or macrophages. The levels of IL-1 $\beta, \mathrm{KC}, \mathrm{MIP}-1 \alpha$ and MIP-2, as well as of the lipid mediator $\mathrm{LTB}_{4}$, were tested by commercial ELISA kits (R\&D Systems) according to the manufacturer's instructions.

Gene expression measurements. For in vitro gene expression studies, $500 \mu \mathrm{l}$ aliquots of $4 \times 10^{6}$ per ml neutrophils suspended in HBSS supplemented with 20 mM HEPES, pH 7.4 were plated on immobilized immune complex surfaces in 24-well tissue culture plates and stimulated for $4 \mathrm{~h}$. The reaction was stopped on ice and the cells (adherent and nonadherent combined) were lysed and total RNA were prepared by the RNeasy Micro Kit (Qiagen). RNA samples were reverse transcripted to cDNA by the cDNA Synthesis Kit (Thermo Scientific) and were kept at $-70^{\circ} \mathrm{C}$ until use. The expression of unique genes was analysed using the TaqMan probes Mm01336189_m1 (Illb), Mm00433859_m1 (Cxcl1), Mm00436450_m1 (Cxcl2), Mm00441258_m1 (Ccl3), Mm01182747 (Alox5), Mm00802100_m1 (Alox5ap), Mm00521826_m1 (Lta4h) and 4352932E (Gapdh) (all from Applied Biosystems) on a Roche LightCycler 480 device in a white 96-well plate. Global gene expression was measured by Affymetrix Microarrays at the UD GenoMed (Debrecen, Hungary) according to the manufacturer $s$ instructions. More information and the raw data files are available in the Gene Expression Omnibus database under the accession number GSE78066.

Biochemical studies. For analysis of Syk phosphorylation, $6 \times 10^{6}$ neutrophils in $1.2 \mathrm{ml}$ assay buffer were plated on immune complex-covered $6-\mathrm{cm}$ tissue culture dishes and incubated for $10 \mathrm{~min}$ at $37^{\circ} \mathrm{C}$. The reaction was stopped on ice and the cells (adherent and nonadherent combined) were lysed in $100 \mathrm{mM} \mathrm{NaCl}, 30 \mathrm{mM}$ Na-HEPES (pH 7.4), $20 \mathrm{mM} \mathrm{NaF,} 1 \mathrm{mM}$ Na-EGTA, $1 \%$ Triton X-100, $1 \mathrm{mM}$ benzamidine, freshly supplemented with $0.1 \mathrm{U} \mathrm{ml}^{-1}$ Aprotinin, 1:100 Mammalian Protease Inhibitor Cocktail, 1:100 Phosphatase Inhibitor Cocktail 2, $1 \mathrm{mM}$ phenylmethylsulphonyl fluoride and $1 \mathrm{mM} \mathrm{Na}_{3} \mathrm{VO}_{4}$ (all from Sigma). After removal of insoluble material, lysates were either boiled in sample buffer or processed for immunoprecipitation. Immunoprecipitation of Syk was performed by an anti-Syk antibody (Clone: 5F5; BioLegend; final concentration: $4.4 \mu \mathrm{g} \mathrm{ml}^{-1}$ ) followed by a capturing step with Protein G-Agarose (Invitrogen) as described $^{57-59}$.

For analysis of IкB $\alpha$ phosphorylation and degradation, $2 \times 10^{6}$ neutrophils in $0.5 \mathrm{ml}$ assay buffer were plated on immune complex-covered 24-well tissue culture plates and incubated for $20 \mathrm{~min}$ at $37^{\circ} \mathrm{C}$. The reaction was stopped on ice and the cells were lysed as described above. During the electrophoretic mobility shift assay, $\mathrm{NF \kappa B}$ activation and nuclear translocation was followed using the same setup, but the cells were lysed with NP40 in the presence of dithiothreitol and phenylmethylsulphonyl fluoride. Nuclear extracts were prepared and were run on an acrylamide gel in the presence of infrared dye-labelled NFKB-binding-sitecontaining oligonucleotides (Licor) as described before ${ }^{8}$.

To test the efficacy of neutrophil-specific CARD9 deletion, neutrophils from mice of different genotypes were sorted on the basis of their Ly6G-staining on a FACSAria flow cytometer (BD Biosciences) from red blood cell-lysed bone marrow cell suspensions.

Whole cell lysates and immunoprecipitates were run on SDS-polyacrylamide gel electrophoresis and immunoblotted using antibodies against phosphotyrosine (Clone: 4G10, Merck Millipore; final concentration: $1 \mu \mathrm{g} \mathrm{ml}^{-1}$ ), Syk (Clone: N19, Santa Cruz Biotechnology; final concentration: $0.2 \mu \mathrm{g} \mathrm{ml}^{-1}$ ), I $\mathrm{B} \alpha$ (Cell Signaling; dilution: 1:1,000), phospho- I $\mathrm{B} \alpha$ (Cell Signaling, dilution: 1:1,000), CARD9 (Clone: H-90, Santa Cruz Biotechnology; final concentration: $0.2 \mu \mathrm{g} \mathrm{ml}^{-1}$ ), Bcl10 (Clone: H-197, Santa Cruz Biotechnology; final concentration: $0.2 \mu \mathrm{g} \mathrm{ml}^{-1}$ ) or $\beta$-actin (Clone: AC-74, Sigma; dilution: 1:5,000) followed by peroxidase-labelled secondary antibodies (GE Healthcare; dilution: 1:5,000). The signal was developed using the ECL system (GE Healthcare) and exposed to X-ray film. Western blots with more details are available in Supplementary Fig. 10.

Presentation of the data and statistical analysis. Experiments were performed the indicated number of times. Quantitative graphs and kinetic curves show mean and s.e.m. from all independent in vitro experiments or from all individual mice from the indicated number of experiments. Unless otherwise stated, statistical analyses were carried out using two-way (factorial) ANOVA, with treatment and genotype being the two independent variables. In case of kinetic assays, area under the curve was used for statistical analysis. $P$ values below 0.05 were considered statistically significant.

\section{References}

1. Mantovani, A., Cassatella, M. A., Costantini, C. \& Jaillon, S. Neutrophils in the activation and regulation of innate and adaptive immunity. Nat. Rev. Immunol. 11, 519-531 (2011).

2. Németh, T. \& Mócsai, A. The role of neutrophils in autoimmune diseases. Immunol. Lett. 143, 9-19 (2012).

3. Mócsai, A. Diverse novel functions of neutrophils in immunity, inflammation, and beyond. J. Exp. Med. 210, 1283-1299 (2013).

4. Yipp, B. G. et al. Infection-induced NETosis is a dynamic process involving neutrophil multitasking in vivo. Nat. Med. 18, 1386-1393 (2012).

5. Scapini, P. et al. The neutrophil as a cellular source of chemokines. Immunol. Rev. 177, 195-203 (2000).

6. Scapini, P. \& Cassatella, M. A. Social networking of human neutrophils within the immune system. Blood 124, 710-719 (2014).

7. Roth, S. \& Ruland, J. Caspase recruitment domain-containing protein 9 signaling in innate immunity and inflammation. Trends Immunol. 34, 243-250 (2013).

8. Gross, O. et al. Card9 controls a non-TLR signalling pathway for innate anti-fungal immunity. Nature 442, 651-656 (2006).

9. LeibundGut-Landmann, S. et al. Syk- and CARD9-dependent coupling of innate immunity to the induction of $\mathrm{T}$ helper cells that produce interleukin 17 Nat. Immunol. 8, 630-638 (2007).

10. Robinson, M. J. et al. Dectin-2 is a Syk-coupled pattern recognition receptor crucial for Th17 responses to fungal infection. J. Exp. Med. 206, 2037-2051 (2009).

11. Glocker, E. O. et al. A homozygous CARD9 mutation in a family with susceptibility to fungal infections. N Engl J Med 361, 1727-1735 (2009) 
12. Drewniak, A. et al. Invasive fungal infection and impaired neutrophil killing in human CARD9 deficiency. Blood 121, 2385-2392 (2013).

13. Roth, S. et al. Rad50-CARD9 interactions link cytosolic DNA sensing to IL-1 $\beta$ production. Nat. Immunol. 15, 538-545 (2014).

14. Zhernakova, A. et al. Genetic analysis of innate immunity in Crohn's disease and ulcerative colitis identifies two susceptibility loci harboring CARD9 and IL18RAP. Am. J. Hum. Genet. 82, 1202-1210 (2008).

15. McGovern, D. P. et al. Genome-wide association identifies multiple ulcerative colitis susceptibility loci. Nat. Genet. 42, 332-337 (2010).

16. Franke, A. et al. Genome-wide meta-analysis increases to 71 the number of confirmed Crohn's disease susceptibility loci. Nat. Genet. 42, 1118-1125 (2010).

17. Rivas, M. A. et al. Deep resequencing of GWAS loci identifies independent rare variants associated with inflammatory bowel disease. Nat. Genet. 43, 1066-1073 (2011).

18. Pointon, J. J. et al. Elucidating the chromosome 9 association with AS; CARD9 is a candidate gene. Genes Immun. 11, 490-496 (2010).

19. Evans, D. M. et al. Interaction between ERAP1 and HLA-B27 in ankylosing spondylitis implicates peptide handling in the mechanism for HLA-B27 in disease susceptibility. Nat. Genet. 43, 761-767 (2011).

20. Arya, R. et al. Genetic variants influencing joint damage in Mexican Americans and European Americans with rheumatoid arthritis. Genet. Epidemiol. 39, 678-688 (2015)

21. Kiryluk, K. et al. Discovery of new risk loci for IgA nephropathy implicates genes involved in immunity against intestinal pathogens. Nat. Genet. 46, 1187-1196 (2014)

22. Hara, H. et al. The adaptor protein CARD9 is essential for the activation of myeloid cells through ITAM-associated and Toll-like receptors. Nat. Immunol. 8, 619-629 (2007)

23. Heng, T. S. et al. Immunological Genome Project, C. The Immunological Genome Project: networks of gene expression in immune cells. Nat. Immunol. 9, 1091-1094 (2008)

24. Korganow, A. S. et al. From systemic T cell self-reactivity to organspecific autoimmune disease via immunoglobulins. Immunity 10, 451-461 (1999).

25. Sitaru, C. et al. Induction of dermal-epidermal separation in mice by passive transfer of antibodies specific to type VII collagen. J. Clin. Invest. 115, 870-878 (2005).

26. Liu, Z. et al. A passive transfer model of the organ-specific autoimmune disease, bullous pemphigoid, using antibodies generated against the hemidesmosomal antigen, BP180. J. Clin. Invest. 92, 2480-2488 (1993).

27. Chou, R. C. et al. Lipid-cytokine-chemokine cascade drives neutrophil recruitment in a murine model of inflammatory arthritis. Immunity 33, 266-278 (2010).

28. Wipke, B. T. \& Allen, P. M. Essential role of neutrophils in the initiation and progression of a murine model of rheumatoid arthritis. J. Immunol. 167, 1601-1608 (2001).

29. Cremasco, V., Graham, D. B., Novack, D. V., Swat, W. \& Faccio, R. Vav/Phospholipase C $\gamma 2$-mediated control of a neutrophil-dependent murine model of rheumatoid arthritis. Arthritis Rheum. 58, 2712-2722 (2008).

30. Jakus, Z., Simon, E., Frommhold, D., Sperandio, M. \& Mócsai, A. Critical role of phospholipase $\mathrm{C} \gamma 2$ in integrin and Fc receptor-mediated neutrophil functions and the effector phase of autoimmune arthritis. J. Exp. Med. 206, 577-593 (2009).

31. Jakus, Z., Simon, E., Balázs, B. \& Mócsai, A. Genetic deficiency of Syk protects mice from autoantibody-induced arthritis. Arthritis Rheum. 62, 1899-1910 (2010).

32. Kovács, M. et al. The Src family kinases Hck, Fgr, and Lyn are critical for the generation of the in vivo inflammatory environment without a direct role in leukocyte recruitment. J. Exp. Med. 211, 1993-2011 (2014).

33. Skarnes, W. C. et al. A conditional knockout resource for the genome-wide study of mouse gene function. Nature 474, 337-342 (2011).

34. Chiriac, M. T. et al. NADPH oxidase is required for neutrophil-dependent autoantibody-induced tissue damage. J. Pathol. 212, 56-65 (2007).

35. Passegue, E., Wagner, E. F. \& Weissman, I. L. JunB deficiency leads to a myeloproliferative disorder arising from hematopoietic stem cells. Cell 119, 431-443 (2004)

36. Abram, C. L., Roberge, G. L., Hu, Y. \& Lowell, C. A. Comparative analysis of the efficiency and specificity of myeloid-Cre deleting strains using ROSA-EYFP reporter mice. J. Immunol. Methods 408, 89-100 (2014).

37. Elliott, E. R. et al. Deletion of Syk in neutrophils prevents immune complex arthritis. J. Immunol. 187, 4319-4330 (2011).

38. Li, L. et al. IL-17 produced by neutrophils regulates IFN- $\gamma$-mediated neutrophil migration in mouse kidney ischemia-reperfusion injury. J. Clin. Invest. 120, 331-342 (2010)

39. Monach, P. A. et al. Neutrophils in a mouse model of autoantibodymediated arthritis: critical producers of Fc receptor $\gamma$, the receptor for C5a, and lymphocyte function-associated antigen 1. Arthritis Rheum. 62, 753-764 (2010).

40. Lai, K. N. Pathogenesis of IgA nephropathy. Nat. Rev. Nephrol. 8, 275-283 (2012).

41. Bakema, J. E. \& van Egmond, M. The human immunoglobulin A Fc receptor Fc $\alpha$ RI: a multifaceted regulator of mucosal immunity. Mucosal Immunol. 4, 612-624 (2011).

42. Mócsai, A., Walzog, B. \& Lowell, C. A. Intracellular signalling during neutrophil recruitment. Cardiovasc. Res. 107, 373-385 (2015).

43. Futosi, K., Fodor, S. \& Mócsai, A. Neutrophil cell surface receptors and their intracellular signal transduction pathways. Int. Immunopharmacol. 17, 638-650 (2013).

44. Blonska, M. \& Lin, X. NF- $\kappa$ B signaling pathways regulated by CARMA family of scaffold proteins. Cell Res. 21, 55-70 (2011).

45. Jiang, C. \& Lin, X. Regulation of NF- $\kappa$ B by the CARD proteins. Immunol. Rev. 246, 141-153 (2012).

46. Ruland, J. et al. Bcl10 is a positive regulator of antigen receptor-induced activation of NF-KB and neural tube closure. Cell 104, 33-42 (2001).

47. Wang, D. et al. Phospholipase $\mathrm{C} \gamma 2$ is essential in the functions of B cell and several Fc receptors. Immunity 13, 25-35 (2000).

48. Lowell, C. A., Soriano, P. \& Varmus, H. E. Functional overlap in the $s r c$ gene family: inactivation of $h c k$ and $f g r$ impairs natural immunity. Genes Dev. 8, 387-398 (1994).

49. Chan, V. W., Meng, F., Soriano, P., DeFranco, A. L. \& Lowell, C. A. Characterization of the B lymphocyte populations in Lyn-deficient mice and the role of Lyn in signal initiation and down-regulation. Immunity 7, 69-81 (1997).

50. Farley, F. W., Soriano, P., Steffen, L. S. \& Dymecki, S. M. Widespread recombinase expression using FLPeR (flipper) mice. Genesis 28, 106-110 (2000).

51. Kouskoff, V. et al. Organ-specific disease provoked by systemic autoimmunity. Cell 87, 811-822 (1996).

52. Csorba, K. et al. Cross-reactivity of autoantibodies from patients with epidermolysis bullosa acquisita with murine collagen VII. Cell. Mol. Life Sci. 67, 1343-1351 (2010).

53. Mócsai, A. et al. G-protein-coupled receptor signaling in Syk-deficient neutrophils and mast cells. Blood 101, 4155-4163 (2003).

54. Kertész, Z. et al. Phospholipase $\mathrm{C} \gamma 2$ is required for basal but not oestrogen deficiency-induced bone resorption. Eur. J. Clin. Invest. 42, 49-60 (2012).

55. Jakus, Z., Németh, T., Verbeek, J. S. \& Mócsai, A. Critical but overlapping role of Fc $\gamma$ RIII and Fc $\gamma$ RIV in activation of murine neutrophils by immobilized immune complexes. J. Immunol. 180, 618-629 (2008).

56. Németh, T. et al. Neutrophil functions and autoimmune arthritis in the absence of p190RhoGAP: Generation and analysis of a novel null mutation in mice. J. Immunol. 185, 3064-3075 (2010).

57. Mócsai, A. et al. Kinase pathways in chemoattractant-induced degranulation of neutrophils: The role of $\mathrm{p} 38$ mitogen-activated protein kinase activated by Src family kinases. J. Immunol. 164, 4321-4331 (2000).

58. Mócsai, A. et al. The immunomodulatory adapter proteins DAP12 and Fc receptor $\gamma$-chain $(\mathrm{FcR} \gamma)$ regulate development of functional osteoclasts through the Syk tyrosine kinase. Proc. Natl Acad. Sci. USA 101, 6158-6163 (2004).

59. Mócsai, A. et al. Integrin signaling in neutrophils and macrophages uses adaptors containing immunoreceptor tyrosine-based activation motifs. Nat. Immunol. 7, 1326-1333 (2006).

\section{Acknowledgements}

We thank Edina Simon for expert technical assistance; Kinga Csorba, Olivér Vilinovszk and Kata Szilveszter for help with experiments; Szilárd Póliska and Bálint L. Bálint for assistance with the Affymetrix studies; Gábor Bánhegyi for access to equipment; Diane Mathis, Christophe Benoist, Clifford Lowell, Victor Tybulewicz, James Ihle, Emmanuelle Passegue and the Wellcome Trust Sanger Institute for transgenic animals; Jeffrey Ravetch and Falk Nimmerjahn for the Fc $\gamma$ RIV mAbs. This work was supported by the European Research Council (Starting Independent Investigator Award No. 206283 to A.M.), the European Union's FP7 Cooperation Program (TARKINAID project to A.M. and C.S.), the Lendület program of the Hungarian Academy of Sciences (LP2013-66/2013 to A.M.) and the János Bolyai Research Scholarship of the Hungarian Academy of Sciences (to T.N.). A.M. was a recipient of a Wellcome Trust International Senior Research Fellowship (Grant No. 087782). K.F. was a recipient of a Hungarian National Excellence Program (TÁMOP 4.2.4. A/1-11-1-2012-0001) research fellowship co-funded by the EU's European Social Fund.

\section{Author contributions}

T.N. and A.M. conceived the study, designed the experiments and wrote the manuscript T.N. and K.F. performed the experiments. T.N., K.F. and A.M. analysed and interpreted 
the data. C.S. and J.R. provided experimental tools and scientific advice. A.M. supervised the project.

\section{Additional information}

Supplementary Information accompanies this paper at http://www.nature.com/

naturecommunications

Competing financial interests: The authors declare no competing financial interests.

Reprints and permission information is available online at http://npg.nature.com/ reprintsandpermissions/
How to cite this article: Németh, T. et al. Neutrophil-specific deletion of the CARD9 gene expression regulator suppresses autoantibody-induced inflammation in vivo. Nat. Commun. 7:11004 doi: 10.1038/ncomms11004 (2016).

(c) (i) This work is licensed under a Creative Commons Attribution 4.0 International License. The images or other third party material in this article are included in the article's Creative Commons license, unless indicated otherwise in the credit line; if the material is not included under the Creative Commons license, users will need to obtain permission from the license holder to reproduce the material. To view a copy of this license, visit http://creativecommons.org/licenses/by/4.0/ 